\title{
Heavy Rainfall Duration Bias in Dynamical Downscaling and Its Related Synoptic Patterns in Summertime Asian Monsoon
}

\author{
YUTA TAMAKI \\ Graduate School of Science, Hokkaido University, Sapporo, Japan \\ MASARU INATSU \\ Faculty of Science, Hokkaido University, Sapporo, Japan \\ DZung NGuyen-Le And Tomohito J. YAmadA \\ Faculty of Engineering, Hokkaido University, Sapporo, Japan
}

(Manuscript received 27 April 2017, in final form 2 May 2018)

\begin{abstract}
Dynamical downscaling (DDS) was conducted over Japan by using a regional atmospheric model with reanalysis data to investigate the rainfall duration bias over Kyushu, Japan, in July and August from 2006 to 2015. The model results showed that DDS had a positive rainfall duration bias over Kyushu and a dry bias over almost all of Kyushu, which were emphasized for extreme rainfall events. Investigated was the rainfall duration bias for heavy rainfall days, accompanied by synoptic-scale forcing, in which daily precipitation exceeded $30 \mathrm{~mm} \mathrm{day}^{-1}$ and covered over $20 \%$ of the Kyushu area. Heavy rainfall days were sampled from observed rainfall data that were based on rain gauge and radar observations. A set of daily climatic variables of horizontal wind and equivalent potential temperature at $850 \mathrm{hPa}$ and sea level pressure, around southwestern Japan, corresponding to the sampled dates, was selected to conduct a self-organizing map (SOM) and $K$-means method. The SOM and $K$-means method objectively classified three synoptic patterns related to heavy rainfall over Kyushu: strong monsoon, weak monsoon, and typhoon patterns. Rainfall duration had a positive bias in western Kyushu for the strong monsoon pattern and a positive bias in southern and east-coast Kyushu for the typhoon pattern, whereas there was little rainfall duration bias in the weak monsoon pattern. The bias for the typhoon pattern was related to rainfall events with a strong rainfall peak. The results suggest that bias correction for rainfall duration would be required for accurately estimating direct runoff in a catchment area in addition to the precipitation amount.
\end{abstract}

\section{Introduction}

Sudden heavy rainfall causes natural disasters, including flooding and inundation, landslides, erosion, and high tides. There has been a great concern about observational studies that showed a recent increase in heavy precipitation over North America (DeGaetano 2009; Pryor et al. 2009), Europe (Bartholy and Pongrácz 2007; Maraun et al. 2008; Zolina et al. 2009), and Asia (Fujibe et al. 2006; Rajeevan et al. 2008). It is anticipated that a wetter climate caused by global warming would result in a greater chance of heavy rainfall (Donat et al. 2016). A series of adaptation policies should be compiled to prepare for possible hazards due to more frequent heavy

Corresponding author: Yuta Tamaki, tamaki@sci.hokudai.ac.jp rainfall, and thus a high-resolution dataset for the precipitation change is highly required. Recently, dynamical downscaling (DDS; Giorgi 1990) has been used to fill the gap between the coarse resolution of the global climate model projection and the provincial scale of social demand. The DDS has the advantage of physical consistency over a model domain, but it contains model bias that results from the unrealistic topography and physical parameterizations, including cloud physics, convective parameterization, and boundary layer schemes, in both the general circulation model (GCM) and the regional climate model (RCM; Ehret et al. 2012; Wang et al. 2004). Therefore, we need to correct the model bias before estimating future changes from the DDS results.

A bias correction for daily and monthly precipitation amount has typically been made. Shifting and scaling 
(a) Terrain elevation in NHM

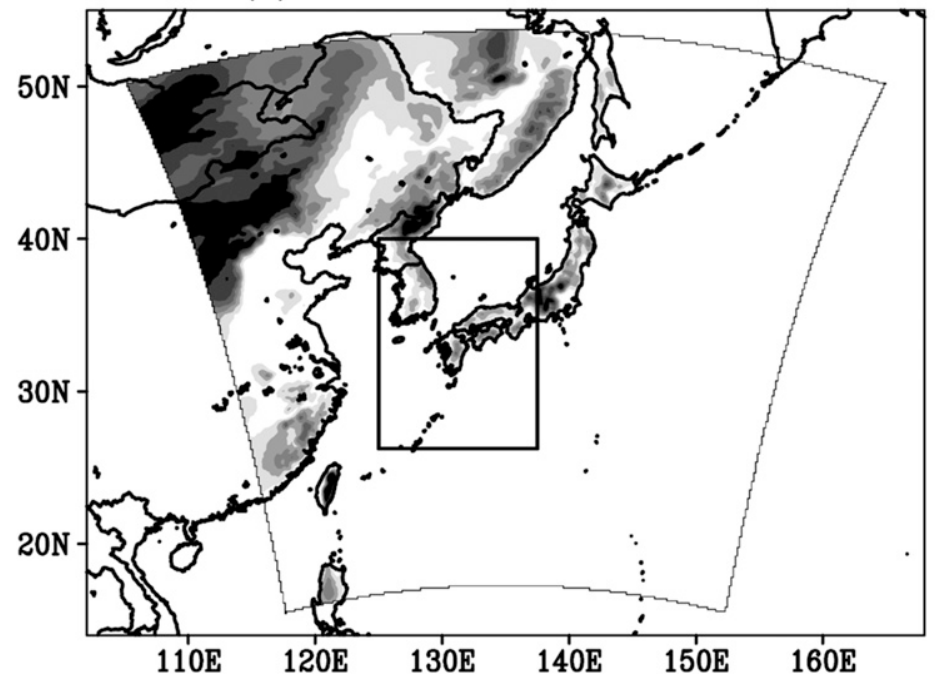

(b) Terrain elavation Kyushu

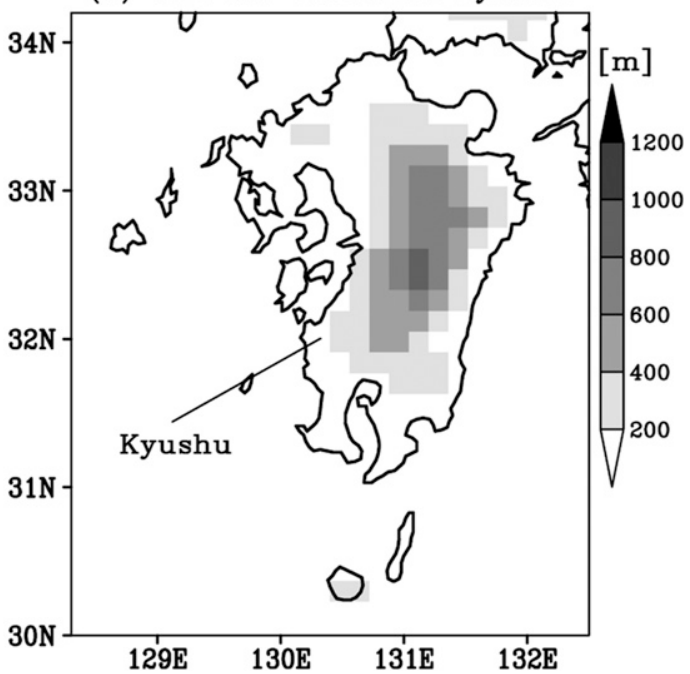

FIG. 1. (a) Terrain elevation in the NHM domain, and (b) magnification over Kyushu. The shading scale is shown on the right. The inner solid-outlined box in (a) shows the domain for our SOM.

(Leander and Buishand 2007; Prudhomme et al. 2002; Shabalova et al. 2003) and quantile mapping (Ines and Hansen 2006; Themeß1 et al. 2011; Piani et al. 2010) are two major methods of bias correction to daily or monthly precipitation amount. The former method scales model precipitation amount to match its climatology with observations (Shabalova et al. 2003). This method is not always suitable for heavy rainfall, however, because the estimate is highly sensitive to the scaling factor (Berg et al. 2012; Leander and Buishand 2007). The latter method adjusts the precipitation amount to maintain consistency in a cumulative distribution function between the model and the observation. The quantile mapping tends to smooth the local-scale variability (Maraun 2013). Note here that there is no way to make a correction if the regional atmospheric model (RAM) simulates no rainfall.

When the bias correction is applied to the DDS output such as temperature or precipitation amount in future climate, the correction coefficient in quantile mapping or shifting and scaling is obtained from the climatic variable in the bias correction based on the current climate simulation. This method implicitly assumes that the model bias is time invariant. However, this stationary assumption is questionable (Christensen et al. 2008; Maraun 2012; Maraun et al. 2010). Li et al. (2018) proposed a bias correction method according to synoptic patterns related to heavy precipitation amount. They detected heavy rainfall events on the basis of the rain gauge data and classified the synoptic patterns related to heavy rainfall events using a self-organizing map (SOM; Kohonen 1982) with an input parameter of sea level pressure (SLP). They then applied quantile mapping to daily precipitation with respect to the corresponding synoptic pattern. Their bias correction approach for precipitation amount may provide a possible way to overcome this stationary assumption problem in bias correction.

On the other hand, there is only one study that attempted the correction method for rainfall duration bias. Nyeko-Ogiramoi et al. (2012) defined the length of consecutive wet days as a wet spell and corrected the mean of the wet spell by extending additional wet days

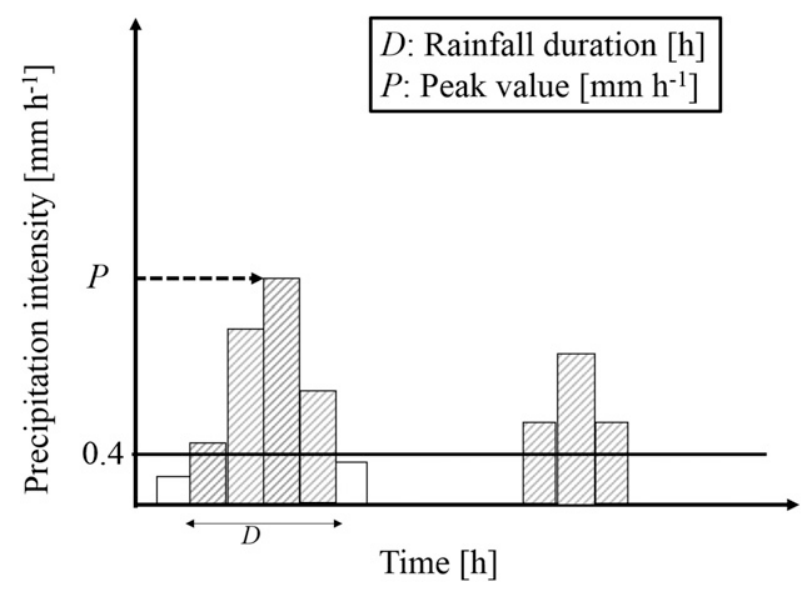

FIG. 2. Schematic diagram for the definition of rainfall duration $D(\mathrm{~h})$ and peak value $P\left(\mathrm{~mm} \mathrm{~h}^{-1}\right)$ of a particular grid point in Kyushu. The sequences of hatched bars are regarded as single rainfall events. 
(a) Precipitation RA

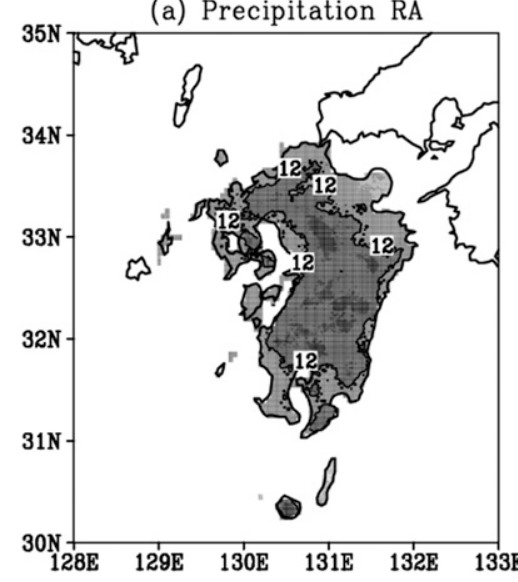

(b) Precipitation DDS

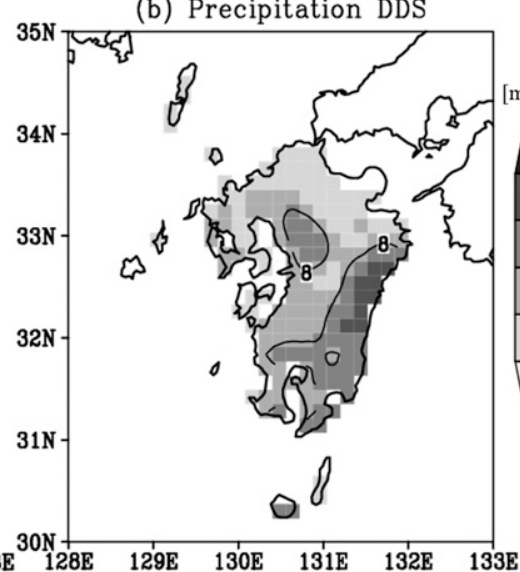

(c) Relative error of DDS [\%]

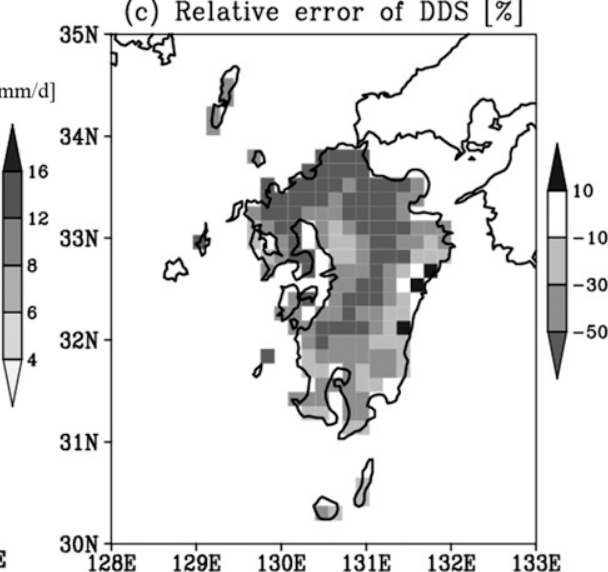

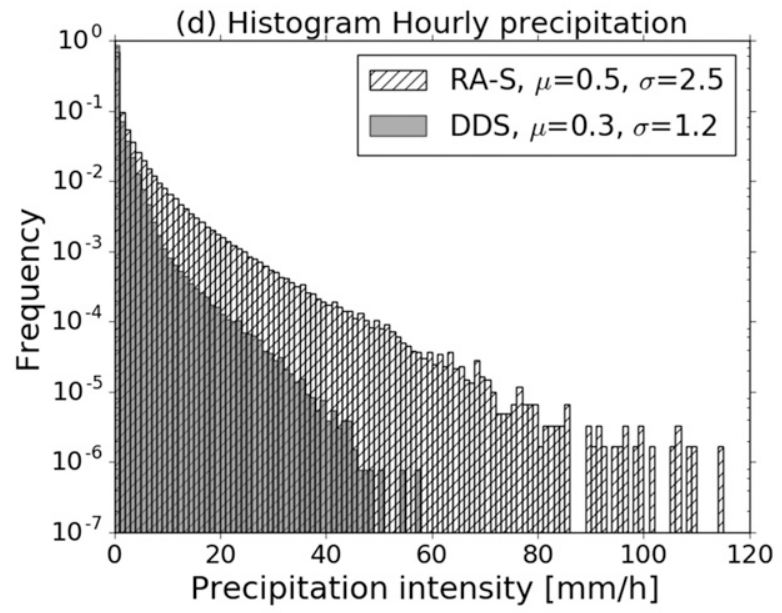

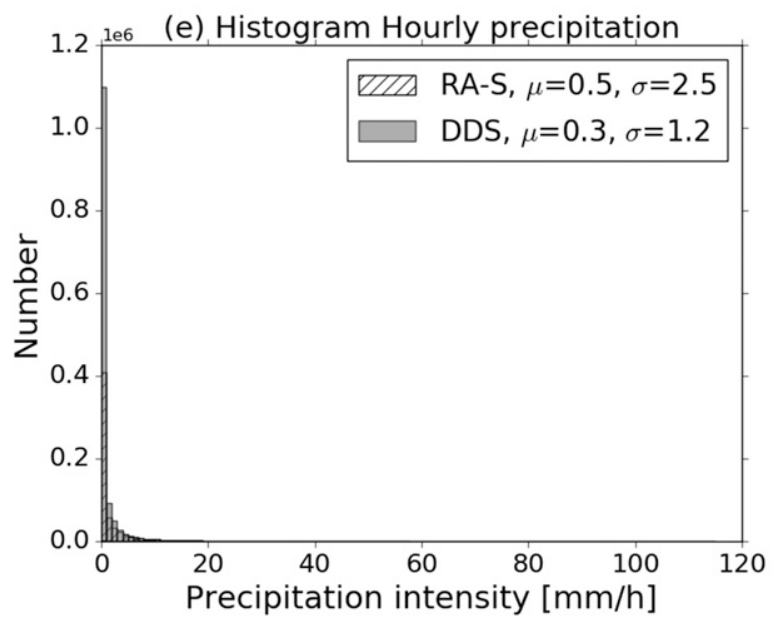

FIG. 3. July-August mean precipitation $\left(\mathrm{mm} \mathrm{day}^{-1}\right.$ ) for (a) Radar/Rain Gauge-Analyzed Precipitation and (b) dynamical downscaling, with the shading scale to the right of (b). The contour shows $12 \mathrm{~mm} \mathrm{day}^{-1}$ in (a) and $8 \mathrm{~mm} \mathrm{day}^{-1}$ in (b). (c) Relative error of DDS (\%) in the July-August mean precipitation, with the shading scale on the right. (d) Histograms of hourly precipitation (mm $\mathrm{h}^{-1}$ ) in RA-S (hatched bars) and DDS (gray bars) over Kyushu. The bin width is set to $1 \mathrm{~mm} \mathrm{~h}^{-1}$, and mean $\mu$ and standard deviation $\sigma$ are provided in the legend. (e) As in (d), but the $y$ axis shows the number.

using a kernel density estimation method (Lall et al. 1996) and replacing the end of wet days of a wet spell with dry days. For example, if the rainfall duration changed in a catchment area consisting of a main stream and its branch rivers, the structure of hydrograph in each subcatchment area would be changed depending on the different spatial scale and runoff coefficient of each subcatchment area. At the downstream toe of the main stream, the timing and amount of direct runoff peak can therefore be affected by hydrographs for subcatchments. Maraun (2013) pointed out that the temporal variation of bias-corrected precipitation amount by a quantile mapping was determined for every grid box. He also pointed out that if these precipitation data were to be used in hydrological modeling then the flood risk would be overestimated in narrow, rapidly responding catchments. For the above reason, the bias correction of rainfall duration is important for accurately estimating the direct runoff and flood risk in a catchment area. However, no one has yet explicitly stated how a DDS result contains the precipitation duration bias.

This study aims to provide an explicit description on the rainfall duration bias of a RAM forced with reanalysis data. The knowledge obtained in this paper is useful in that the atmospheric forcing drives a hydrological model to evaluate direct runoff in a catchment, which is often crucial for estimating flood risk. We focus on summertime heavy precipitation over Kyushu, one of the four main islands of Japan as mapped in Fig. 1. Recalling Li et al. (2018), it is natural that a rainfall event has the model bias of the rainfall duration involving its related synoptic pattern. Summertime precipitation in Kyushu is generally controlled by the 
(a) Duration DDS

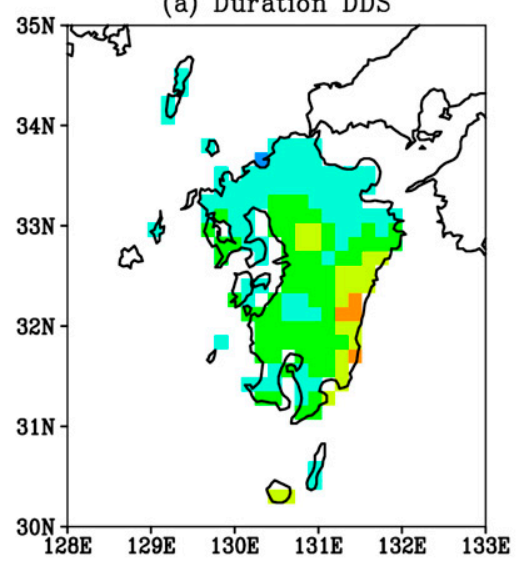

(d) Duration DDS P $>=30[\mathrm{~mm} / \mathrm{h}]$

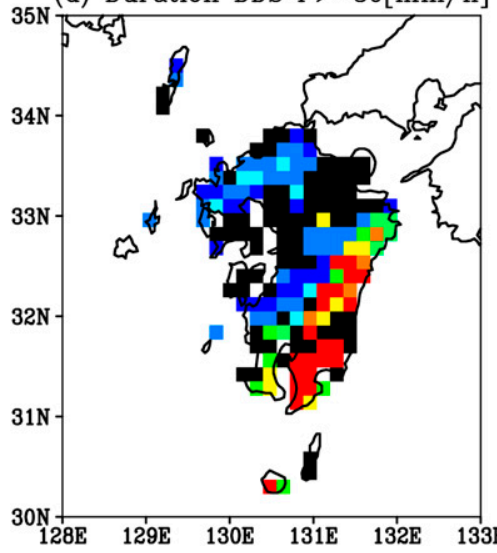

(b) Duration RA-S

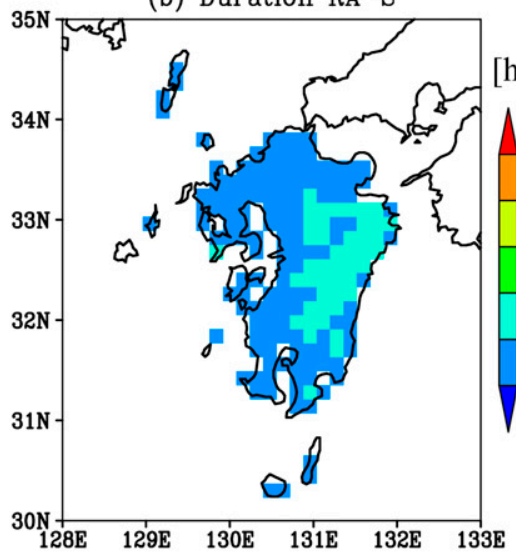

(e) Duration RA-S P $>=30[\mathrm{~mm} / \mathrm{h}]$

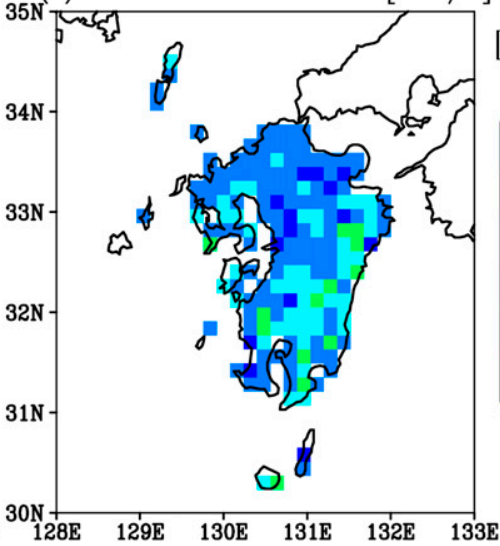

(c) Duration DDS minus RA-S

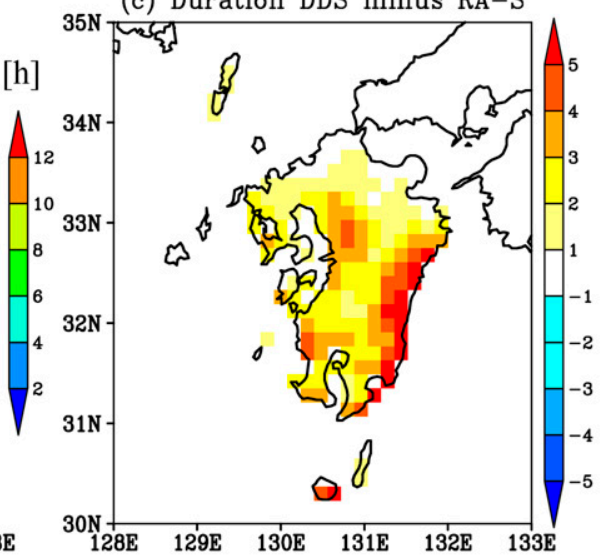

(f) diff. Duration $\mathrm{P}>=30[\mathrm{~mm} / \mathrm{h}]$

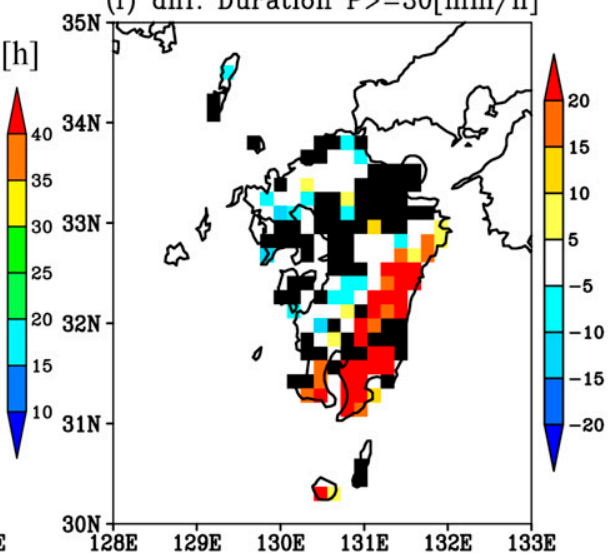

FIG. 4. Average rainfall duration (h) for (a) DDS and (b) RA-S for all rainfall events during July and August from 2006 to 2015 , and (c) the difference between DDS and RA-S for average rainfall duration (h). (d)-(f) As in (a)-(c), but for rainfall events for which the peak value exceeds $30 \mathrm{~mm} \mathrm{~h}^{-1}$. Black shading in (d) and (f) shows locations at which no rainfall event had its peak value exceed $30 \mathrm{~mm} \mathrm{~h}^{-1}$.

low-level moisture intrusion related to the Asian monsoon and typhoon passages. We apply SOM to detect typical synoptic patterns related to heavy rainfall days in Kyushu and link the patterns with rainfall duration biases. This paper is organized as follows: section 2 describes the data and method, section 3 clearly describes the precipitation duration bias in the DDS experiments and performs the SOM analysis to reveal the relationship between heavy rainfall days and surrounding atmospheric environment, and sections 4 and 5 provide discussion and conclusions.

\section{Data and method}

\section{a. Observations}

The rainfall observation data are the Radar/Rain Gauge-Analyzed Precipitation (RA), which is based on 46 C-band radars operated by the Japan Meteorological Agency (JMA) and the Ministry of Land, Infrastructure,
Transport and Tourism (MLIT) and approximately 10000 rain gauges of the JMA, MLIT, and local governments [see Nagata (2011) for details], which have been intensively used as the verification data in many publications without additional quality controls (cf. Oki and Sumi 1994; Iida et al. 2006). The horizontal resolution of RA is $1 \mathrm{~km}$ and the analysis period is July and August from 2006 to 2015. The RA provides 1-h accumulated precipitation amount $(\mathrm{mm})$ with the minimum unit of $0.4 \mathrm{~mm} \mathrm{~h}^{-1}$. We regard the 1 -h accumulated precipitation amount of RA as precipitation intensity $\left(\mathrm{mm} \mathrm{h}^{-1}\right)$. This study focuses on Kyushu, with 38869 RA grid points over the land originally. For comparison of RA with model results, we also use the original RA data with a subsample for which the horizontal resolution is approximately $15 \mathrm{~km}$, as fine as the RAM used in this study (section 2b). Hereinafter, the subsampled RA is referred to as RA-S, with 181 grid points over Kyushu. We also use, as the lateral boundary condition for dynamical downscaling, three-dimensional geopotential 
TABLE 1. List of heavy rainfall days for each cluster. Dates with marked with \#, *, and $\dagger$ show transition from or toward clusters $\mathrm{C} 0, \mathrm{C} 1$, and $\mathrm{C} 2$, respectively.

\begin{tabular}{|c|c|c|c|c|c|c|}
\hline \multicolumn{3}{|c|}{$\mathrm{C} 0$} & \multicolumn{2}{|c|}{$\mathrm{C} 1$} & \multicolumn{2}{|c|}{$\mathrm{C} 2$} \\
\hline $1 \mathrm{Jul} 2006$ & 1 Jul 2009 & 3 Jul 2013 & $1 \mathrm{Jul} 2008$ & 2 Jul 2014 & 17 Aug 2006 & $30 \mathrm{Jul} 2014$ \\
\hline 2 Jul 2006 & $10 \mathrm{Jul} 2009^{\#}$ & 6 Jul 2013 & 8 Aug 2008 & 6 Jul 2014 & 18 Aug 2006 & 31 Jul 2014 \\
\hline 4 Jul 2006 & 21 Jul 2009 & $26 \mathrm{Jul} 2013$ & 27 Aug 2008 & 19 Aug 2014 & & 1 Aug 2014 \\
\hline 5 Jul 2006 & 24 Jul 2009 & 4 Aug 2013 & 29 Aug 2008 & 21 Aug 2014 & 12 Jul 2007 & 2 Aug 2014* \\
\hline 6 Jul 2006 & $25 \mathrm{Jul} 2009^{\#}$ & 23 Aug 2013 & & 29 Aug 2014 & $13 \mathrm{Jul} 2007$ & 7 Aug 2014 \\
\hline $19 \mathrm{Jul} 2006$ & & 24 Aug 2013 & $11 \mathrm{Jul} 2009^{\#}$ & & 14 Jul 2007 & 8 Aug 2014 \\
\hline $20 \mathrm{Jul} 2006$ & 2 Jul 2010 & 25 Aug 2013 & $26 \mathrm{Jul} 2009^{\#}$ & 4 Jul 2015 & 2 Aug 2007 & 9 Aug 2014 \\
\hline $21 \mathrm{Jul} 2006$ & 3 Jul 2010 & 30 Aug 2013 & 14 Aug 2009 & $6 \mathrm{Jul} 2015$ & & \\
\hline $22 \mathrm{Jul} 2006$ & 11 Jul 2010" & 31 Aug 2013 & & $20 \mathrm{Jul} 2015$ & 8 Aug 2009 & $11 \mathrm{Jul} 2015^{*}$ \\
\hline 23 Jul 2006 & 28 Jul 2010 & & 8 Jul 2010 & $21 \mathrm{Jul} 2015$ & & 24 Aug 2015 \\
\hline \multirow[t]{2}{*}{31 Aug 2006} & 11 Aug 2010 & 3 Jul 2014 & $10 \mathrm{Jul} 2010^{\#}$ & 22 Jul 2015 & 17 Jul 2011 & \\
\hline & & 9 Jul 2014 & $12 \mathrm{Jul} 2010^{\#}$ & 16 Aug 2015 & 18 Jul 2011 & \\
\hline 1 Jul 2007 & 4 Jul 2011 & 12 Jul 2014 & 13 Jul 2010 & 29 Aug 2015 & 5 Aug 2011 & \\
\hline 2 Jul 2007 & 5 Jul 2011 & 3 Aug 2014* & 14 Jul 2010 & 30 Aug 2015 & 6 Aug 2011 & \\
\hline 3 Jul 2007 & 6 Jul 2011 & 4 Aug 2014 & & 31 Aug 2015 & & \\
\hline 5 Jul 2007 & 14 Aug 2017 & 5 Aug 2014 & 20 Aug 2011 & & 16 Jul 2012 & \\
\hline 6 Jul 2007 & 15 Aug 2017 & & 21 Aug 2011 & & $18 \mathrm{Jul} 2012^{\dagger}$ & \\
\hline 7 Jul 2007 & & 2 Jul 2015 & 22 Aug 2011 & & 1 Aug 2012 & \\
\hline 8 Jul 2007 & 1 Jul 2012 & 12 Jul $2015^{*}$ & 23 Aug 2011 & & 22 Aug 2012 & \\
\hline \multirow[t]{2}{*}{$10 \mathrm{Jul} 2007$} & 2 Jul 2012 & 13 Jul 2015 & & & 26 Aug 2012 & \\
\hline & 4 Jul 2012 & 12 Aug 2015 & $19 \mathrm{Jul} 2012^{\dagger}$ & & 27 Aug 2012* & \\
\hline $17 \mathrm{Jul} 2008$ & 6 Jul 2012 & & $20 \mathrm{Jul} 2012$ & & & \\
\hline 16 Aug 2008 & 11 Jul 2012 & & 22 Jul 2012 & & & \\
\hline 19 Aug 2008 & 12 Jul 2012 & & 10 Aug 2012 & & & \\
\hline \multirow[t]{4}{*}{22 Aug 2008} & 13 Jul 2012 & & & & & \\
\hline & 14 Jul 2012 & & & & & \\
\hline & 13 Aug 2012 & & & & & \\
\hline & 28 Aug 2012* & & & & & \\
\hline
\end{tabular}

height, horizontal wind vector, air temperature, and specific humidity, sea surface temperature, and SLP from 6-h JRA-55 reanalysis data (Kobayashi et al. 2015) originally with the resolution of TL319L60. In the SOM analysis, we use JRA-55 with $1.25^{\circ}$ latitude/longitude grid data (Kobayashi et al. 2015).

\section{b. RAM experiments}

We used the JMA/Meteorological Research Institute nonhydrostatic model (NHM) [see Saito et al. (2006) for more details]. The horizontal resolution is $15 \mathrm{~km}$ with the Lambert conformal projection and there are 23 vertical levels with a terrain-following coordinate system. The model domain covers the area around Japan (Fig. 1a). Several physical processes are implemented in the NHM, including a microphysics scheme (Ikawa and Saito 1991), moisture diffusion (Saito and Ishida 2005), land surface and boundary layer processes (Kumagai 2004a,b), and vertical diffusion (Fujibe et al. 1999). The Kain-Fritsch scheme (Kain and Fritsch 1993) is switched on to compensate for the amount of convective precipitation in the insufficient-resolution model. The NHM is integrated from 28 June to 31 August of each year from 2006 to 2015 with lateral and bottom boundary conditions given by JRA-55 original data. We exclude the period from 28 to 30 June as the model spinup.

\section{c. Classification of synoptic patterns related to heavy rainfall}

To classify the synoptic patterns, we use SOM and the $K$-means method. SOM can provide a two-dimensional map with keeping the nonlinear information. After the SOM process, we conduct $K$-means and obtain the synoptic patterns. This combination method of SOM and $K$-means has been used other studies for objectively classifying synoptic patterns (Nguyen-Le et al. 2017; Nishiyama et al. 2007; Ohba et al. 2015, 2016). Our method basically follows Nguyen-Le et al. (2017) and is slightly different from that of Nishiyama et al. (2007), who did not apply the combined empirical orthogonal function (CEOF) analysis before SOM method.

Using daily precipitation from the RA data, we sample days on which the number of grid boxes with daily precipitation of each grid surpassing $30 \mathrm{~mm} \mathrm{day}^{-1}$ exceeds $20 \%$ of the total number of grid boxes over Kyushu. We regard these detected days as "heavy rainfall days." The area of $20 \%$ of Kyushu is set to focus 
(a) Composite SLP EPT850 U850 V850 C0

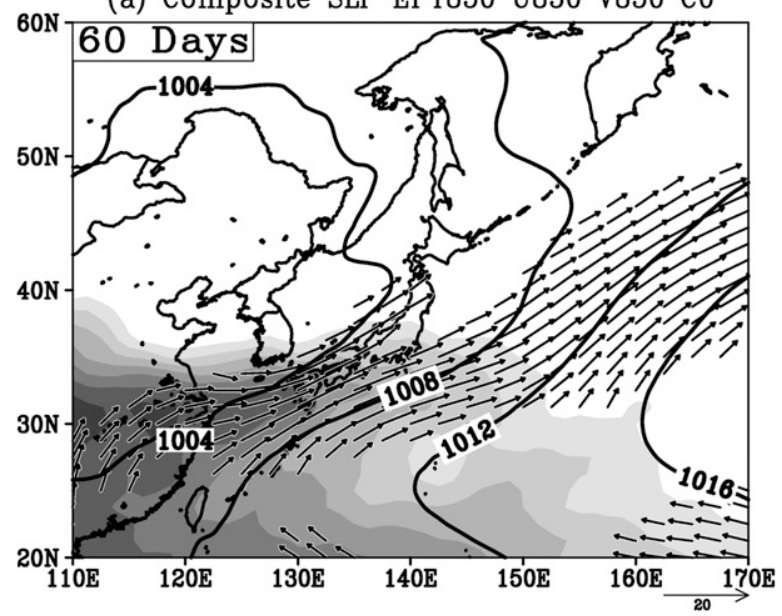

(c) Composite SLP EPT850 U850 V850 C1

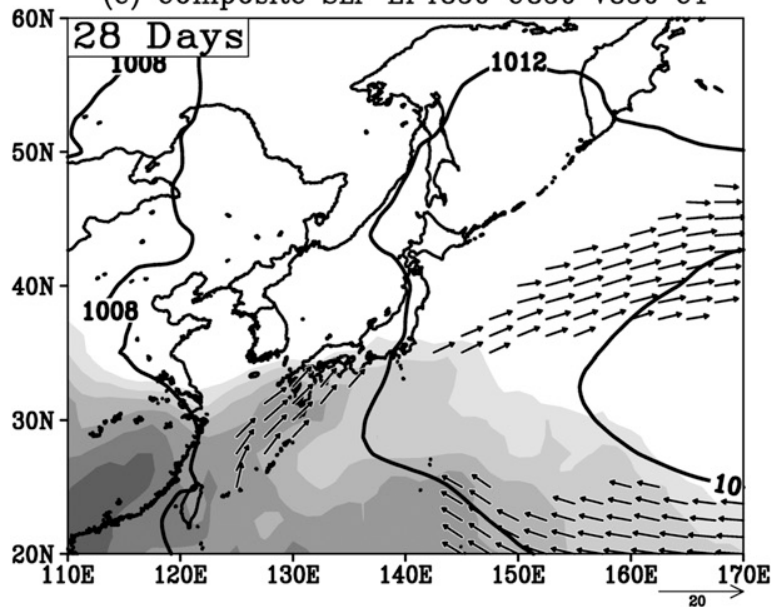

(e) Composite SLP EPT850 U850 V850 C2

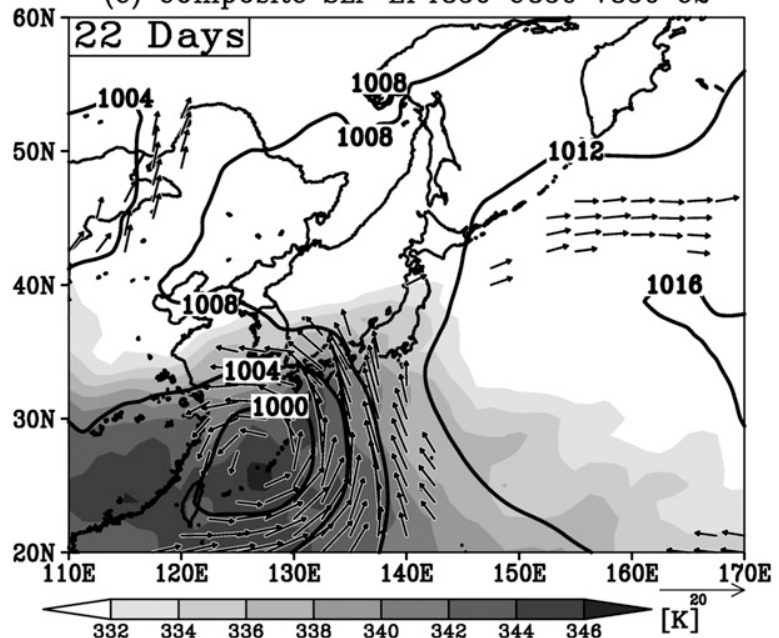

(b) Composite Rainfall RA-S C0

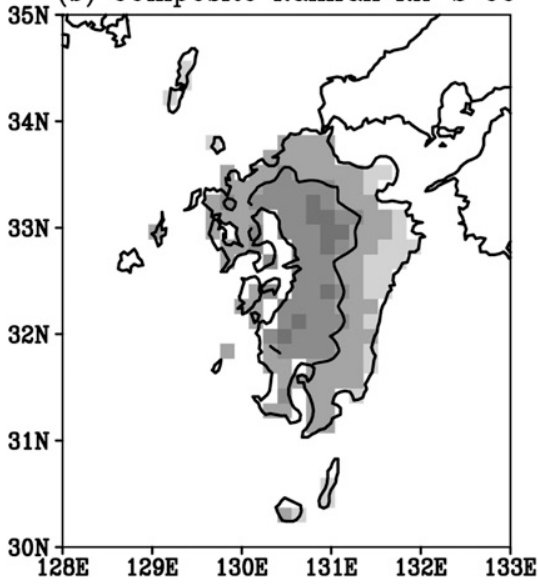

(d) Composite Rainfall RA-S C1

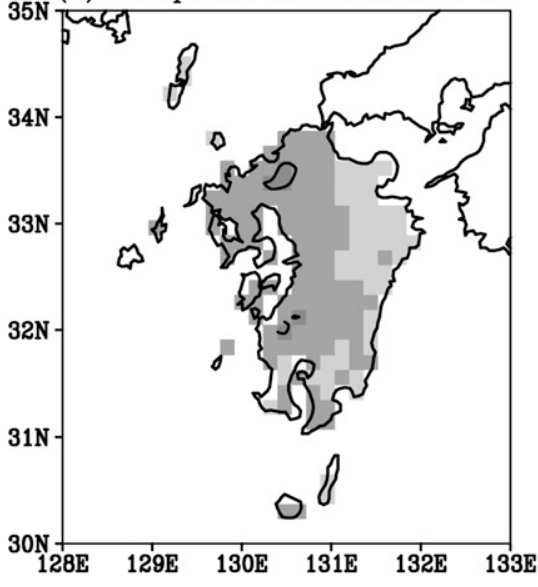

(f) Composite Rainfall RA-S C2

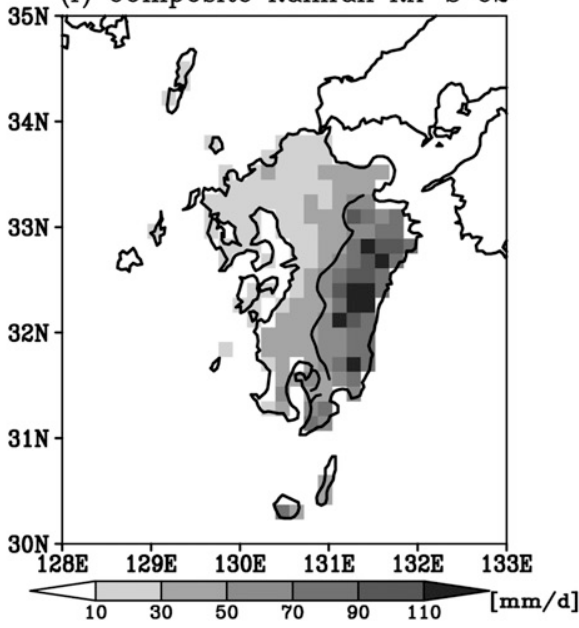

FIG. 5. Composites excluding transition days for clusters (a) C0, (c) C1, and (e) C2 of daily mean SLP (contours; interval is $4 \mathrm{hPa}$ ), 850 -hPa equivalent potential temperature (shading; $\mathrm{K}$ ), and 850 -hPa horizontal wind (vectors; $\mathrm{m} \mathrm{s}^{-1}$ ) from JRA-55 reanalysis data. The shading scale and the unit vector of $20 \mathrm{~m} \mathrm{~s}^{-1}$ are at the bottom of (e), and vectors of $<5 \mathrm{~m} \mathrm{~s}^{-1}$ are omitted. The number of heavy rainfall days is shown in the top-left corner. Also shown are composites for clusters (b) $\mathrm{C} 0$, (d) $\mathrm{C} 1$, and (f) $\mathrm{C} 2$ of RA-S precipitation in Kyushu island (shading; mm day ${ }^{-1}$ ), with $\mathrm{RA}$ precipitation of $50 \mathrm{~mm} \mathrm{day}^{-1}$ being indicated by the contour. 
(a) Composite SLP EPT850 U850 V850 C0

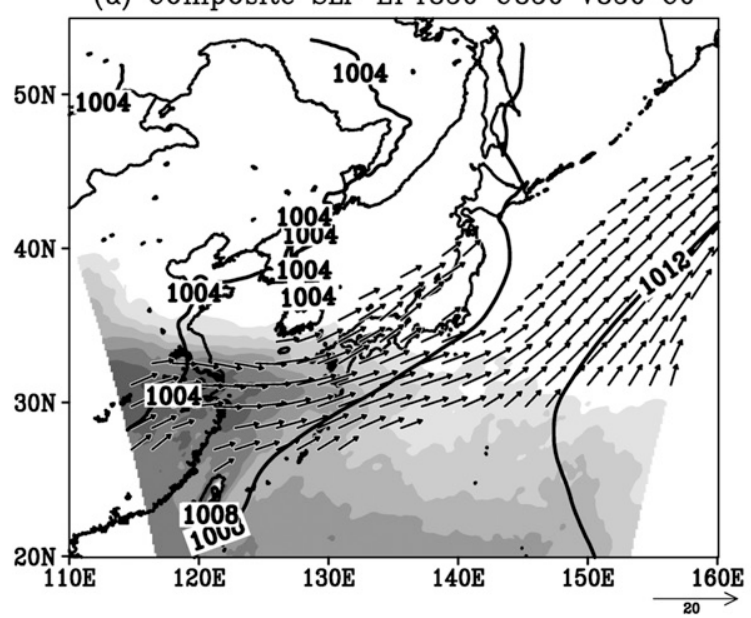

(c) Composite SLP EPT850 U850 V850 C1

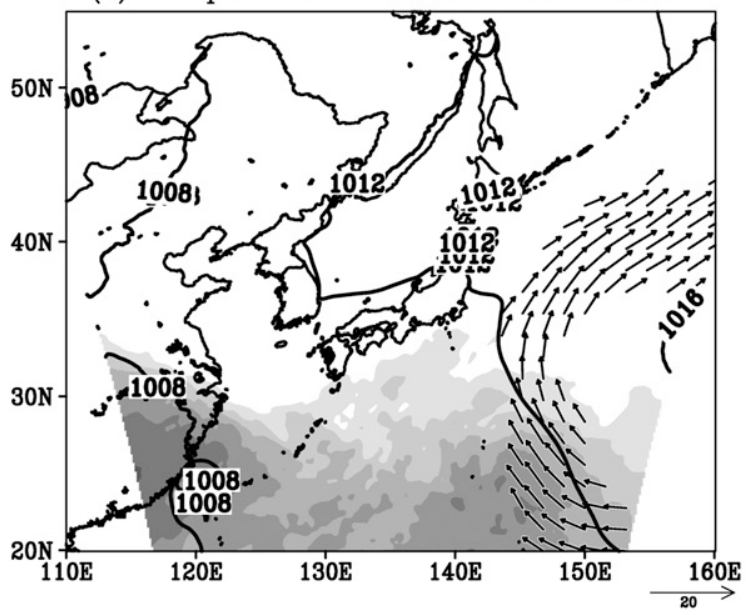

(e) Composite SLP EPT850 U850 V850 C2

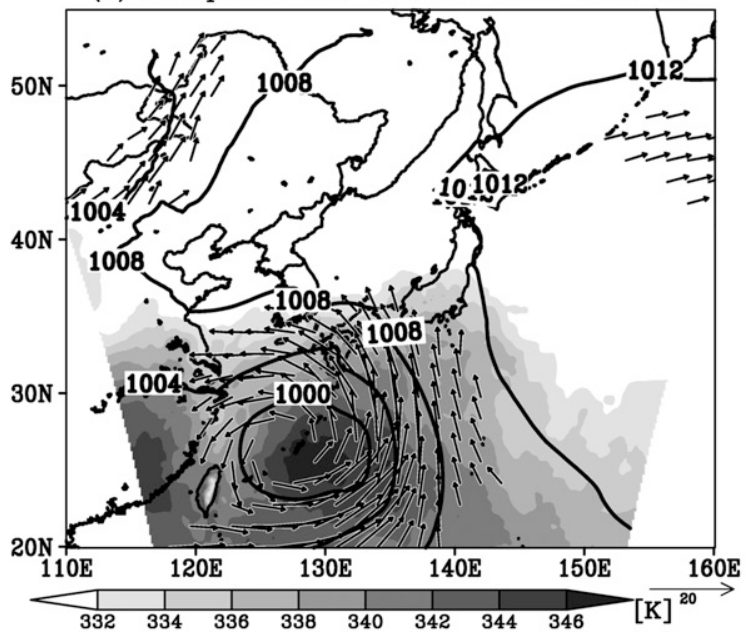

(b) Composite Rainfall DDS C0

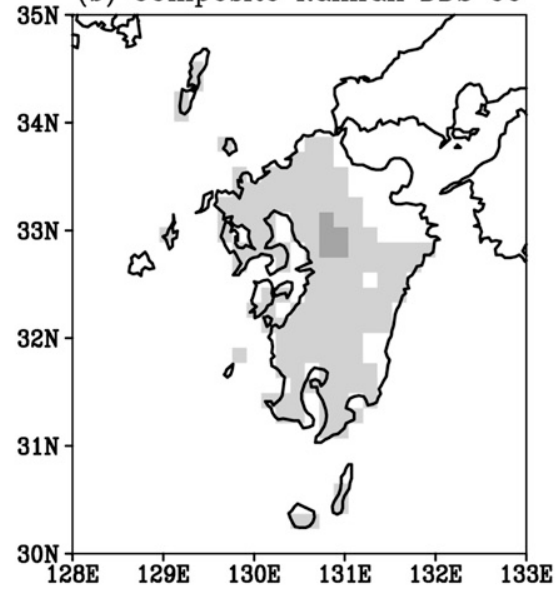

(d) Composite Rainfall DDS C1

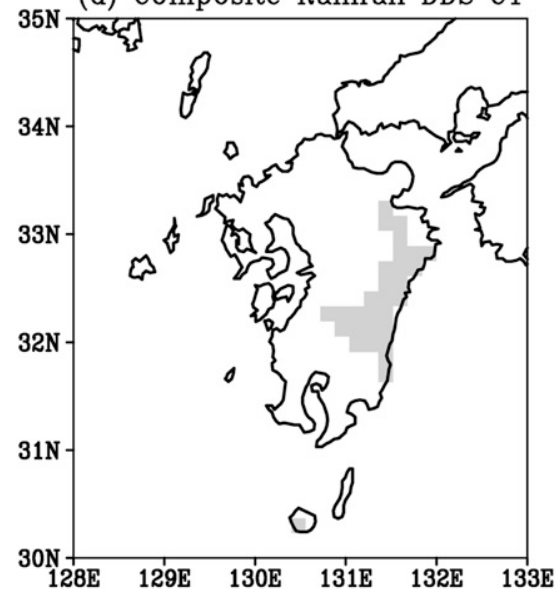

(f) Composite Rainfall DDS C2

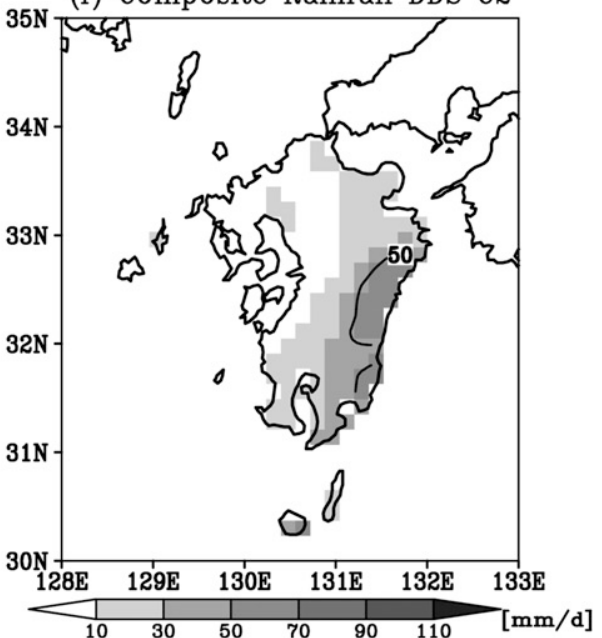

FIG. 6. As in Fig. 5, but for composites of DDS results for the dates classified with SOM on the basis of JRA-55 and RA. 
(a)

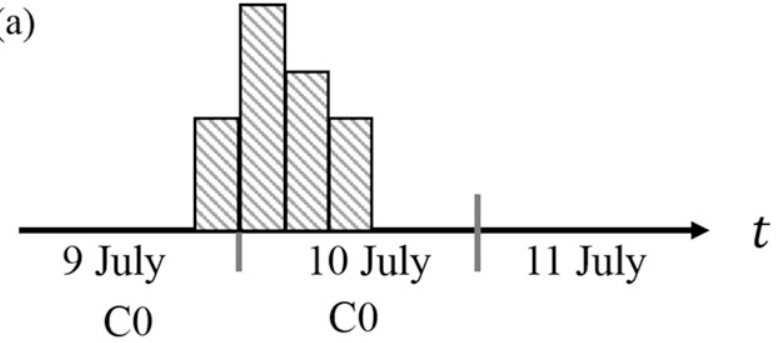

(b)

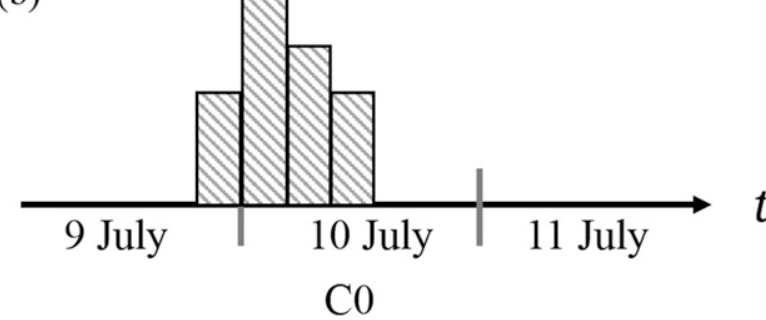

FIG. 7. An example of a continuous rainfall across midnight between 9 and 10 July with (a) both of the dates falling into the same cluster $\mathrm{C} 0$ and (b) one date but not the other falling into cluster $\mathrm{C} 0$.

on the precipitation system forced by large-scale forcing. It is noted that, if a rainfall system such as a typhoon passed midnight and if these two consecutive days satisfy the definition of a heavy rainfall day, we counted two heavy rainfall days. There are 127 heavy rainfall days in the analysis period. The dependency on area coverage of $20 \%$ on our results is discussed in section $4 \mathrm{~b}$. For the selected dates, we prepare a set of daily mean dataset for the following climatic variables from JRA-55 with $1.25^{\circ}$ latitude/longitude grid data: daily-averaged horizontal wind and equivalent potential temperature at $850 \mathrm{hPa}$ and SLP for the domain shown in the box in Fig. 1a. These variables are important for intense precipitation in this region, because it is mainly caused by the mei-yu/ baiu rainband characterized by the strong meridional gradient of equivalent potential temperature and specific humidity (Ninomiya 1984; Ninomiya and Akiyama 1992; Sampe and Xie 2010; Tomita et al. 2011), along with the low-level southwesterly along the western fringe of the North Pacific subtropical high that transports moisture from the tropics (Akiyama 1973; Kodama 1992; Ninomiya 1984, 2000; Ninomiya and Shibagaki 2007). Following Nguyen-Le et al. (2017), for the efficiency of learning processes in SOM, the CEOF analysis of these synoptic variables is performed in advance and 62 leading principal components, for which the explained variance is $99 \%$, are input into the SOM program.

The CEOF analysis of these synoptic variables is performed in advance to reduce the size of input vector from 528 to 62 , noting that the original size is 11 longitude grids times 12 latitude grids times 4 climatic variables of JRA-55. And then, 62 leading principal components are input into the SOM procedure. The results of the SOM analysis are generally sensitive to the number of output nodes. This study fixed it as $10 \times 10$. The node-number dependency is discussed later (section 4b). A Gaussian neighborhood function is used with the learning rate set to 0.2 . To relate the original SOM result to the typical synoptic patterns, we apply the $U$-matrix (Ultsch and Siemon 1990) and $K$-means methods for cluster analysis. Note that the number of cluster is fixed at 3 before conducting $K$-means, because synoptic patterns related to heavy rainfall over Kyushu were mainly categorized into three patterns even with more clusters permitted (not shown). As a consequence, we obtain three typical synoptic patterns related to heavy rainfall over Kyushu.

\section{d. Definition of a rainfall event}

Let us consider a time series of precipitation intensity at a particular grid point in Kyushu (Fig. 2). A single rainfall event is defined as the event in which hourly precipitation continuously exceeds $0.4 \mathrm{~mm} \mathrm{~h}^{-1}$, the minimum unit of RA. The rainfall duration is the period when the rainfall event happens. We also define the peak value $\left(\mathrm{mm} \mathrm{h}^{-1}\right)$ as the maximum precipitation intensity $\left(\mathrm{mm} \mathrm{h}^{-1}\right)$ in the event period.

\section{Results}

\section{a. RAM simulations}

Figures $3 \mathrm{a}$ and $3 \mathrm{~b}$ show the precipitation intensity averaged in July and August (mm day ${ }^{-1}$ ) for RA and DDS. Most of areas in the island seem to exceed $12 \mathrm{~mm}$ day $^{-1}$ around mountain areas with the height over $200 \mathrm{~m}$ in RA (Figs. $1 \mathrm{~b}$ and $3 \mathrm{a}$ ), whereas the precipitation amount in DDS seems to exceed $8 \mathrm{~mm}$ day $^{-1}$ around part of the northwest and along the southeast coast in Kyushu (Fig. 3b). The DDS then underestimates the observed precipitation amount in almost all areas on Kyushu island, with particularly more than $50 \%$ underestimation over part of the central area and almost all parts of the northern area, except for an overestimation of $>10 \%$ along the easternmost coast of Kyushu island (Fig. 3c). Figures $3 \mathrm{~d}$ and $3 \mathrm{e}$ show histograms of hourly precipitation over Kyushu with a bin width of $1 \mathrm{~mm} \mathrm{~h}^{-1}$ and the first bin excluding zero precipitation. A histogram of hourly precipitation over Kyushu reveals that the model underestimates the rainfall with an intensity of $>10 \mathrm{~mm} \mathrm{~h}^{-1}$ and fails to reproduce the very heavy rainfall with an intensity of $>50 \mathrm{~mm} \mathrm{~h}^{-1}$. The RA 
(a) Duration RA-S CO

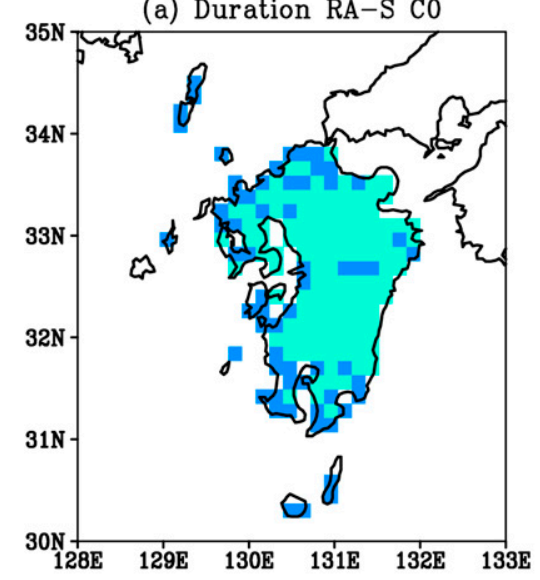

(d) Duration DDS minus RA-S CO

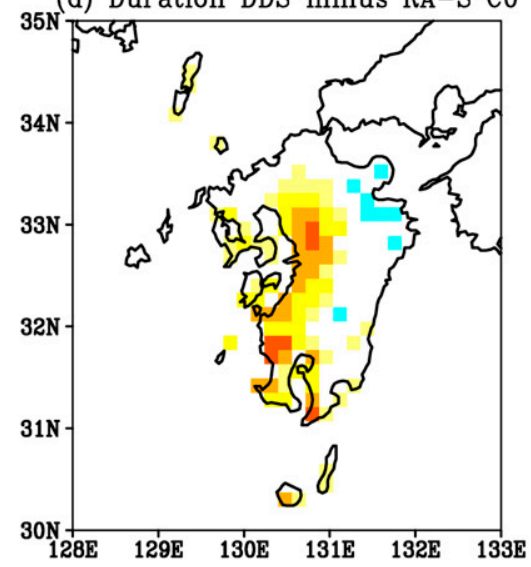

(b) Duration RA-S C1

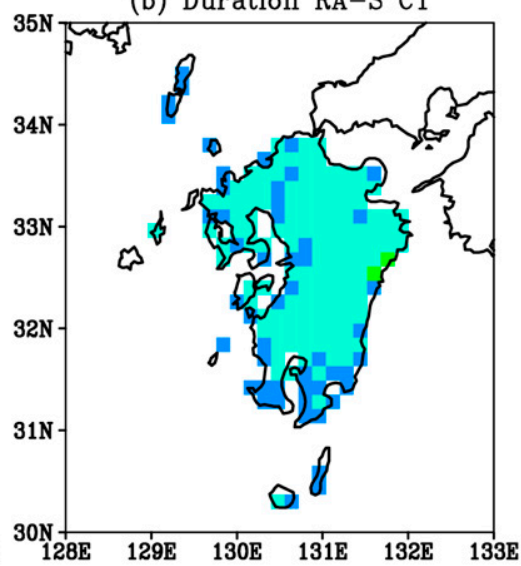

(c) Duration RA-S C2

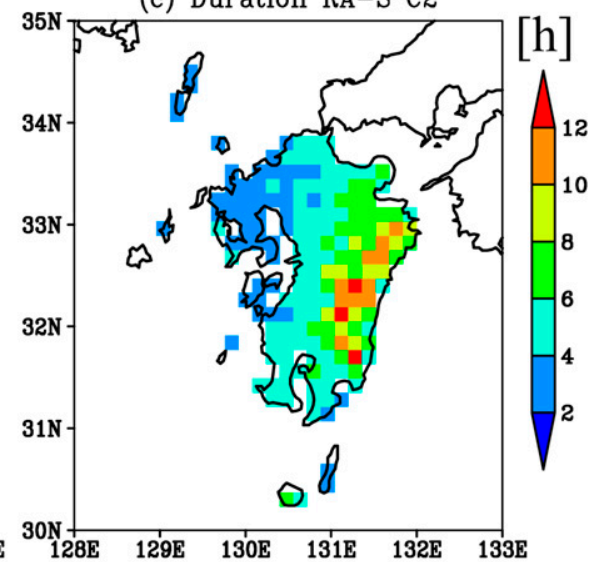

(e) Duration DDS minus RA-S C1

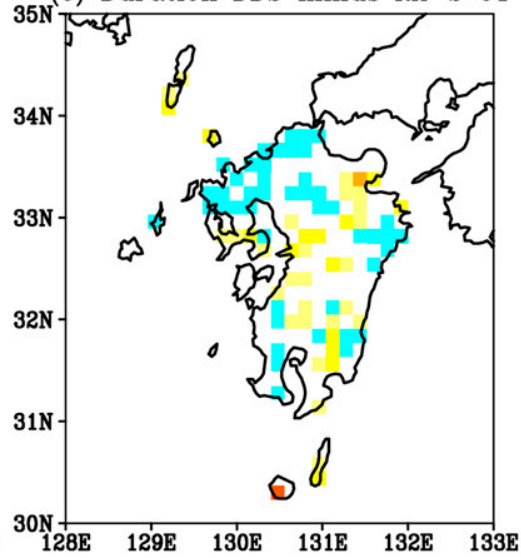

(f) Duration DDS minus RA-S C2

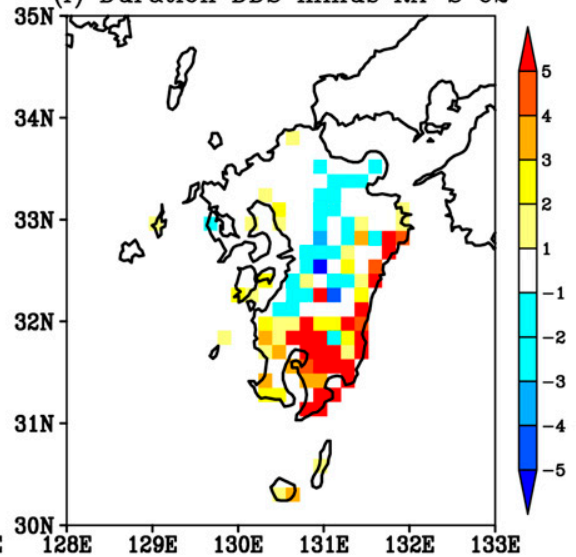

FIG. 8. Average rainfall duration (h) in clusters (a) $\mathrm{C}$, (b) $\mathrm{C} 1$, and (c) $\mathrm{C} 2$, with the shading scale to the right of (c). Also shown is the difference in average rainfall duration (h) between DDS and RA-S (DDS minus RA-S) in clusters (d) C0, (e) C1, and (f) C2.

and DDS precipitation intensity follow the lognormal distribution, but the RA precipitation intensity has a variance that is 2 times that of the DDS precipitation intensity (Fig. 3d). In addition, the DDS has a large positive bias in the frequency of nonzero precipitation (Figs. 3d,e), which is generally called the "drizzle problem" in which GCMs and RCMs simulate too much nonzero precipitation (e.g., Maraun et al. 2010).

The discrepancy between RA and DDS is also obvious in the precipitation duration averaged over the rainfall events, which is the total rainfall durations divided by the number of events. For DDS, two peaks of the average rainfall duration are found on the southeastern side of Kyushu with over $8 \mathrm{~h}$ and on part of the northwest around $33^{\circ} \mathrm{N}, 131^{\circ} \mathrm{E}$ with over $8 \mathrm{~h}$, whereas the average rainfall duration is less than $8 \mathrm{~h}$ over the rest of the region (Fig. 4a). In contrast, the RA-S provides an average rainfall duration ranging from 2 to $6 \mathrm{~h}$ and a small peak with over $4 \mathrm{~h}$ is found on the eastern side of Kyushu (Fig. 4b). The difference therefore shows a positive bias of rainfall duration over Kyushu, with its local maxima located on the eastern side and the northwest area in Kyushu (Fig. 4c). If we restrict rainfall events with peak values over $30 \mathrm{~mm} \mathrm{~h}^{-1}$, the average duration time is prolonged in DDS and RA-S (Figs. 4d,e) and the DDS shows a large positive bias with over $20 \mathrm{~h}$ in the southeastern Kyushu whereas the other areas show relatively little bias (Fig. 4f).

\section{b. Synoptic patterns related to heavy rainfall days}

Table 1 shows the lists of heavy rainfall day in three clusters. We classified $53 \%$ of events as cluster $\mathrm{C} 0,27 \%$ as $\mathrm{C} 1$, and $20 \%$ as $\mathrm{C} 2$. Some consecutive heavy rainfall days across midnight with dates falling into different clusters (see the marked dates in Table 1), called transition cases in this paper, are excluded from our results for simplicity. We will discuss transition cases in section 4 a.

The SOM and $K$-means method produce three clusters for the synoptic patterns related to heavy rainfall 
(a) Rainfall events DDS CO

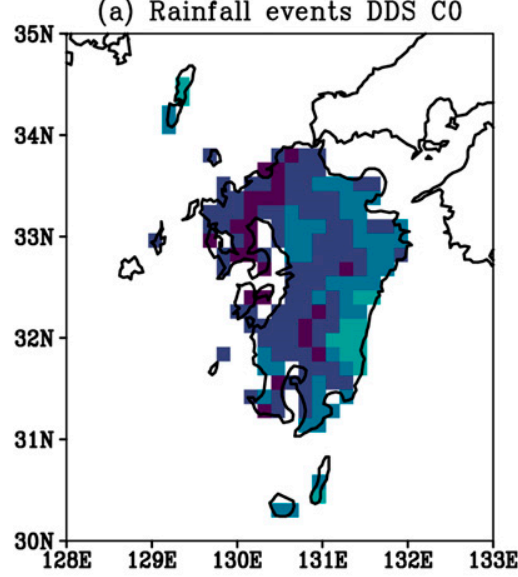

(d) Rainfall events RA-S C0

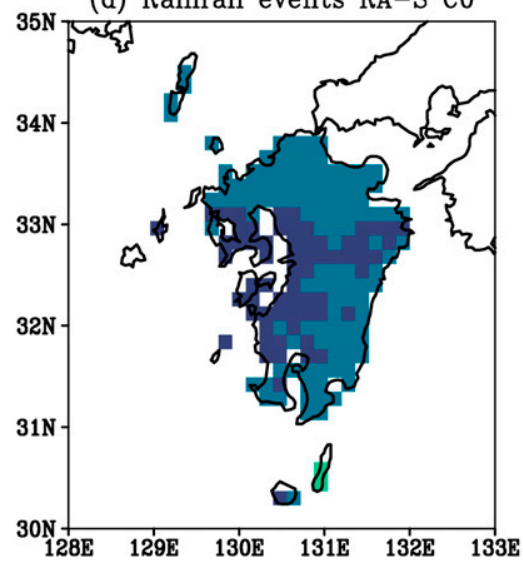

(b) Rainfall events DDS C1

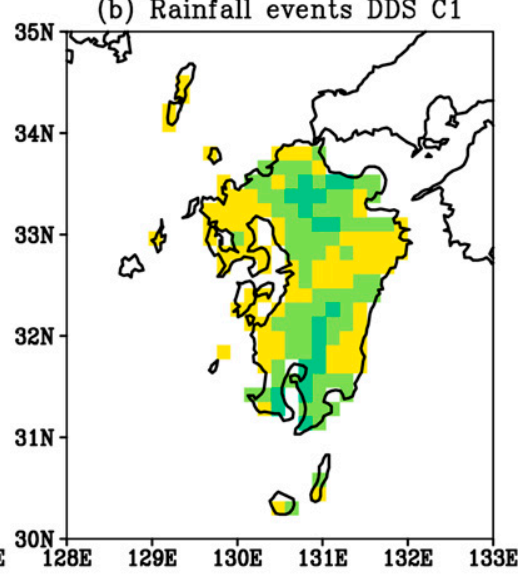

(e) Rainfall events RA-S C1

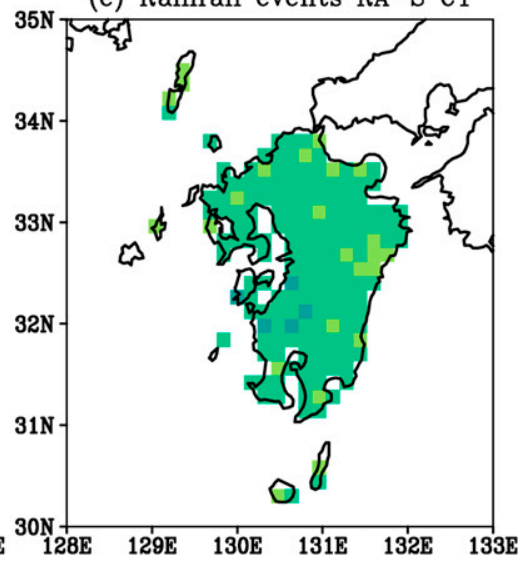

(c) Rainfall events DDS C2

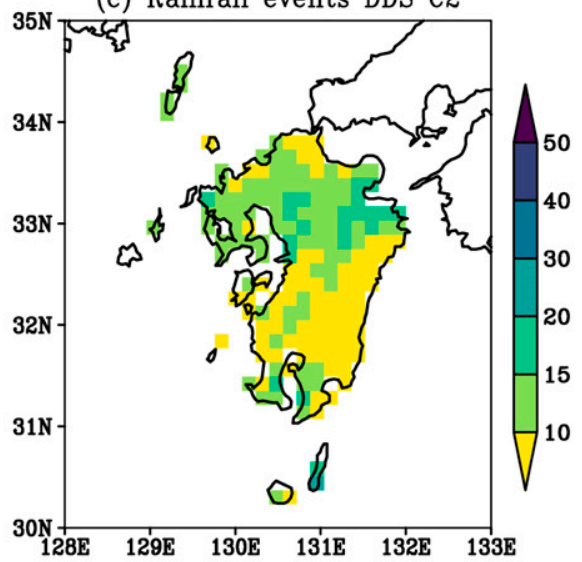

(f) Rainfall events RA-S C2

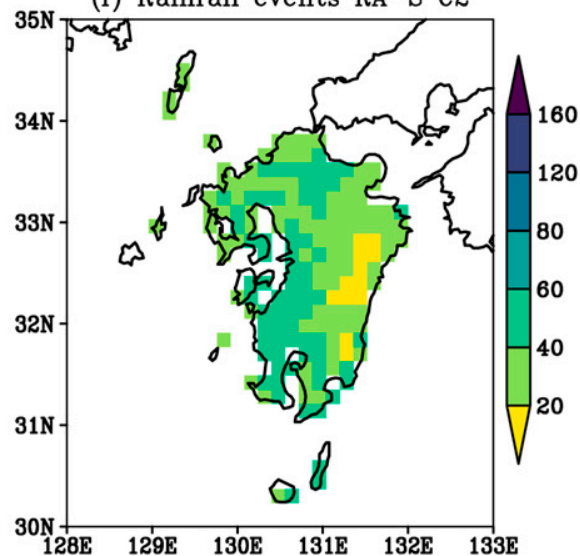

FIG. 9. The number of rainfall events for clusters (a),(d) C0, (b),(e) C1, and (c),(f) C2 in (top) DDS and (bottom) RA-S, with the respective shading scales at the right.

days (Fig. 5). Cluster C0, containing 60 days, is characterized by high equivalent potential temperature air intruding into Kyushu via the low-level jet (LLJ; Matsumoto 1972) and southwesterly along the western ridge of the North Pacific subtropical high. A sharp meridional gradient of equivalent potential temperature extends from the Yellow River basin to northern Kyushu, which can be interpreted as the mei-yu-baiu rainband (Fig. 5a; Ninomiya and Akiyama 1992; Sampe and Xie 2010). These characteristics are similar to the composited synoptic field with SOM in Ohba et al. (2015; see cluster 5 in their Fig. 3), Nguyen-Le et al. (2017; see clusters 1 and 2 in their Fig. 2), and Nishiyama et al. (2007; see clusters 5, 6, and 8 in their Fig. 9). The composited pattern for daily precipitation in Kyushu (Fig. 5b) shows more than $50 \mathrm{~mm}$ day $^{-1}$ over western Kyushu related to the $\mathrm{C} 0$ cluster pattern. Cluster $\mathrm{C} 1$ suppresses the intensity of the LLJ, a westward extension of the North Pacific subtropical high, and the intrusion of warm moist air toward Japan (Fig. 5c). The precipitation amount over Kyushu (Fig. 5d) is less prominent than in cluster $\mathrm{C} 0$. Although the LLJ and southwesterly along the North Pacific subtropical high are suppressed, these characteristics of synoptic pattern are similar to the composite synoptic fields from SOM in Nguyen-Le et al. (2017; see cluster 3 in their Fig. 2) and Nishiyama et al. (2007; see cluster 2 in their Fig. 9). In contrast to clusters $\mathrm{C} 0$ and $\mathrm{C} 1$, cluster $\mathrm{C} 2$ shows strong cyclonic circulation over the East China Sea that transports warm, moist air to Kyushu (Fig. 5e). This typhoon pattern was also detected in Ohba et al. (2015; see cluster 6 in their Fig. 3). Collating the typhoon record with 22 dates categorized into $\mathrm{C} 2$, the cyclonic circulation is caused by 13 typhoon cases. The pattern brings rainfall of more than $70 \mathrm{~mm} \mathrm{day}^{-1}$ in the southerly wind area of the typhoon (Fig. 5f).

Using the date list for each cluster obtained from the SOM and $K$-means method from JRA-55 and RA (Table 1), synoptic charts and rainfall maps were also composited using DDS output (Fig. 6). Wind circulation 

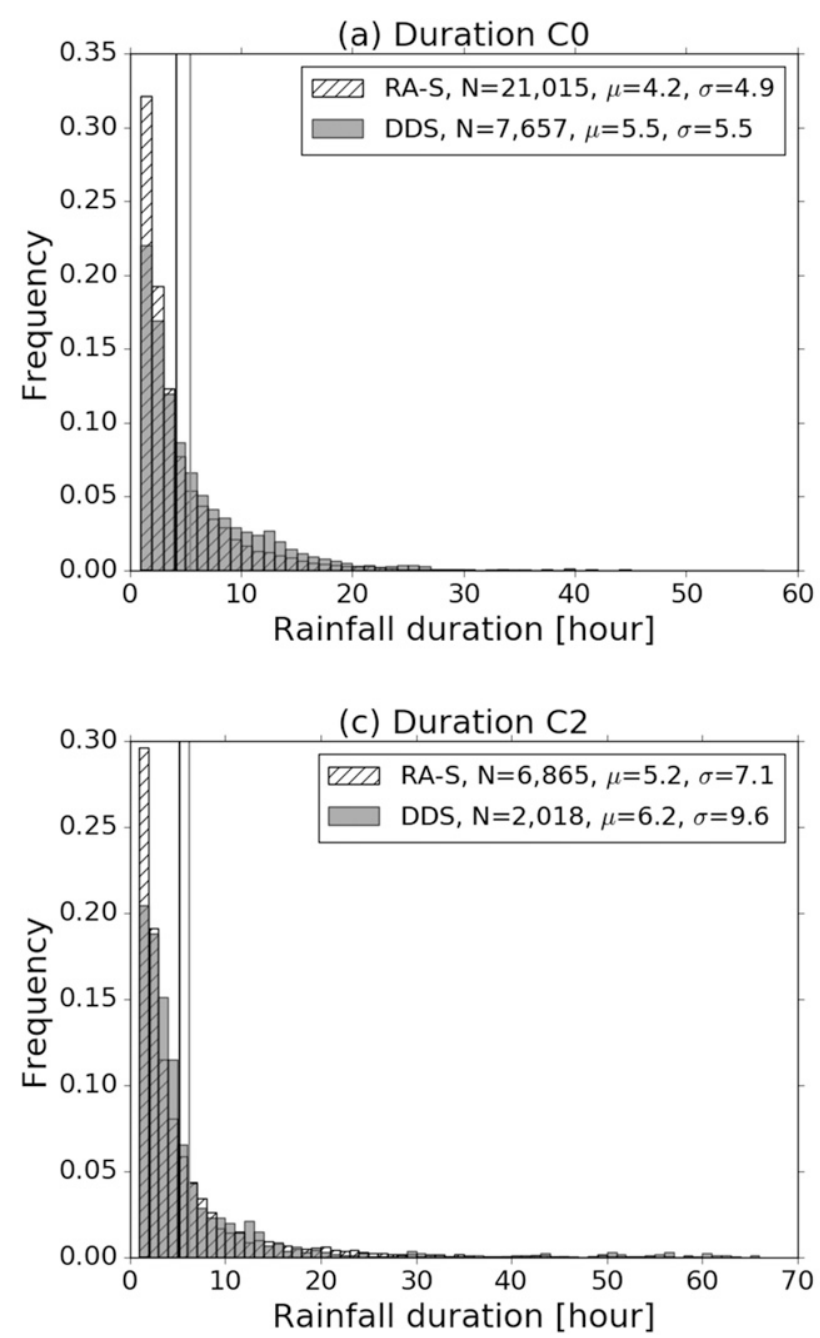

and SLP are similar to the composite maps based on the reanalysis data (Figs. 5a,c,e), although DDS makes drier weather than JRA-55 in cluster C1. The spatial distributions in clusters $\mathrm{C} 0$ and $\mathrm{C} 2$ (Figs. $6 \mathrm{~b}, \mathrm{f}$ ) are similar to the distribution of reanalysis data (Figs. 5b,f), although DDS underestimates the precipitation intensity in almost all areas in Kyushu (Figs. 6b,d,f). Therefore, we conclude that the DDS reproduces a fundamental composite pattern classified with the SOM and $K$ means method.

\section{c. Rainfall duration bias related to heavy rainfall days}

The identification of rainfall event and rainfall duration in each cluster is restricted to dates falling into a particular cluster. Here we consider a time series of hourly rainfall continuously lasting from 2300 UTC 9 July to 0300 UTC 10 July (Fig. 7). When both 9 July and 10 July fall into cluster $\mathrm{C} 0$, the rainfall event is once counted as $\mathrm{C} 0$ and its rainfall duration is $4 \mathrm{~h}$ (Fig. 7a). On

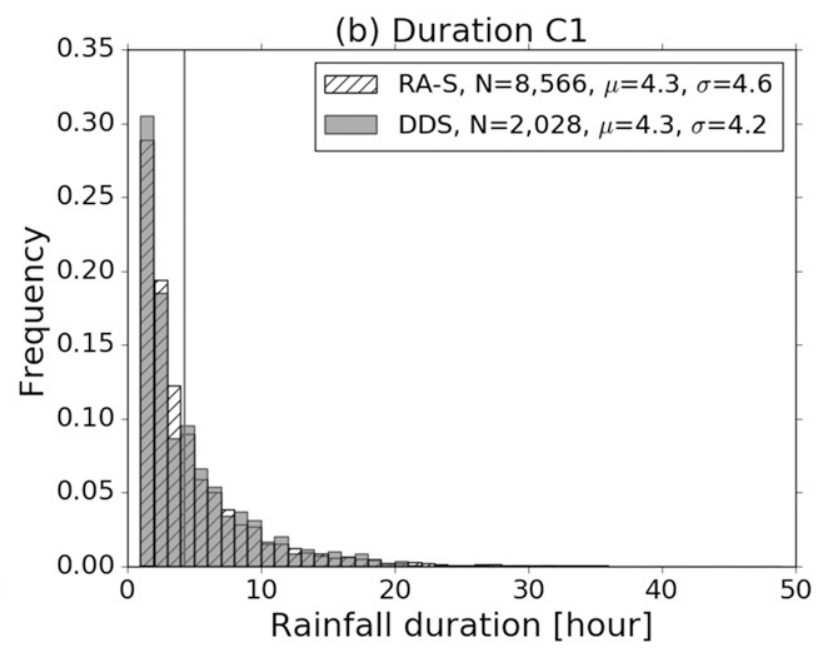

FIG. 10. Histogram of rainfall duration in RA-S (hatched bars) and DDS (gray bars) for clusters (a) C0, (b) C1, and (c) $\mathrm{C} 2$. The bin width is set to $1 \mathrm{~h}$, and the number $N$, the mean $\mu$, and the standard deviation $\sigma$ of the samples are provided in the legends. The means for RA-S and DDS are emphasized by black and gray vertical lines, respectively. the other hand, when only 10 July falls into cluster $\mathrm{C} 0$, the rainfall event is also once counted as cluster $\mathrm{C} 0$ but its rainfall duration is shortened to $3 \mathrm{~h}$ (Fig. 7b).

Figure 8 shows the spatial distribution of average rainfall duration $(\mathrm{h})$ in the three clusters. The average rainfall duration for clusters $\mathrm{C} 0$ and $\mathrm{C} 1$ ranges from 4 to $6 \mathrm{~h}$ in most areas of Kyushu (Figs. 8a,b), whereas the average rainfall duration for cluster $\mathrm{C} 2$ is more than $6 \mathrm{~h}$ in eastern Kyushu and less elsewhere (Fig. 8c). In comparison with RA-S, the DDS almost reproduces the rainfall duration for clusters $\mathrm{C} 0$ and $\mathrm{C} 1$, although it overestimates the rainfall duration of $\mathrm{C} 0$ as $2 \mathrm{~h}$ longer than the observation in western Kyushu (Figs. 8d,e). However, DDS overestimates the rainfall duration of $\mathrm{C} 2$ in southern and east-coast areas in Kyushu (Fig. 8f) as $5 \mathrm{~h}$ longer than the observation. These results are robust because we sampled a sufficient number of rainfall events for clusters C0 and C1 (Figs. 9a,b,d,e) with more than 10 events. Note, however, that cluster $\mathrm{C} 2$ in 

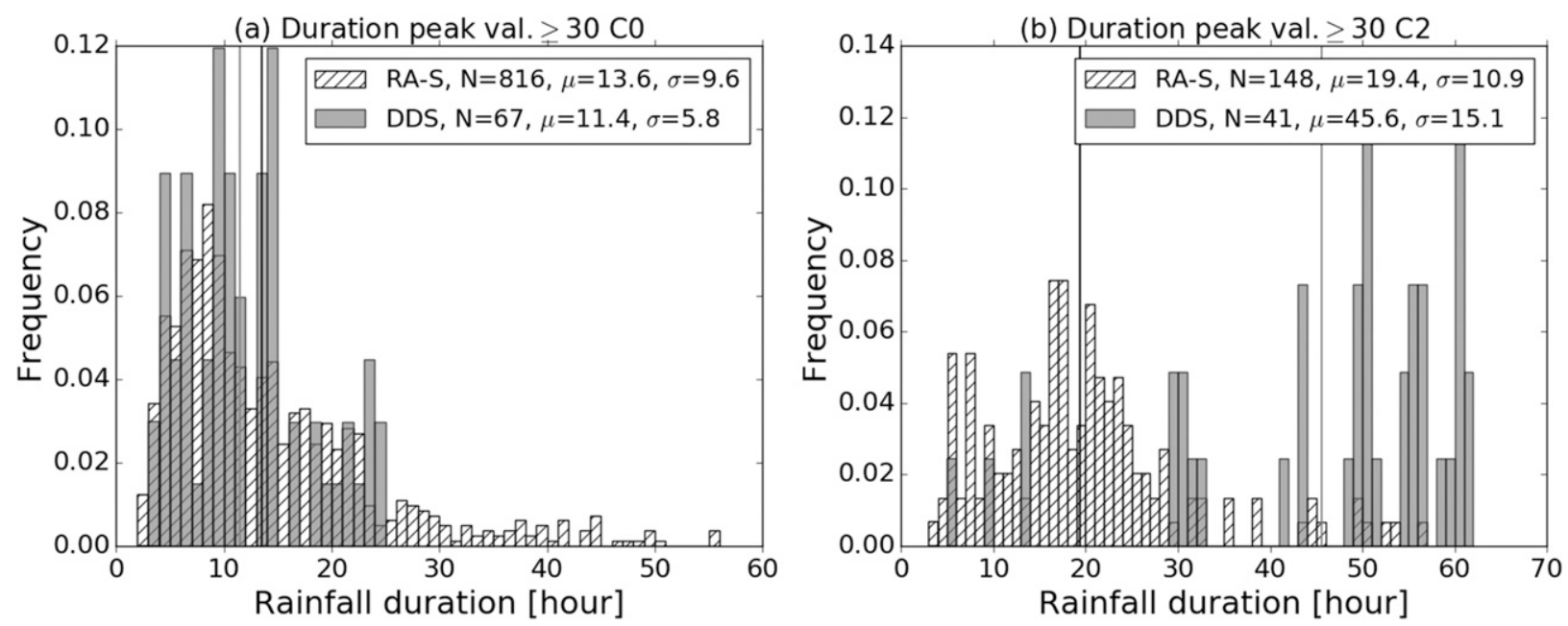

FIG. 11. As in Fig. 10, but for rainfall events for which the peak value exceeds $30 \mathrm{~mm} \mathrm{~h}^{-1}$.

DDS has fewer than 10 rainfall events in southern Kyushu (Fig. 9c).

The histograms of rainfall duration for RA-S and DDS show a lognormal distribution for all clusters (Fig. 10). The mean and standard deviation of cluster C2 are higher than those of the other clusters. The DDS has a positive bias of $1.3 \mathrm{~h}$ in cluster $\mathrm{C} 0$ and of $1.0 \mathrm{~h}$ in cluster C2 (Figs. 10a,c), in spite of little mean bias for cluster C1 (Fig. 10b). This result suggests that the duration bias depends on a synoptic weather pattern that brings heavy rainfall events. Rainfall duration biases among synoptic weather patterns are larger if rainfall is limited to cases with peak values exceeding $30 \mathrm{~mm} \mathrm{~h}^{-1}$ (Fig. 11). The mean and standard deviation of cluster $\mathrm{C} 2$ are higher than for other clusters in both RA-S and DDS (Fig. 11b). In cluster C2, the location of the entire distribution in DDS shifts to the right relative to the one in RA-S. The DDS has a positive bias of $26.2 \mathrm{~h}$ in cluster $\mathrm{C} 2$ (Fig. 11b) and a negative bias of $2.2 \mathrm{~h}$ in cluster $\mathrm{C} 0$ (Fig. 11a).

\section{Discussion}

\section{a. Transition cases}

The numbers of transition events are four cases between cluster $\mathrm{C} 0$ and $\mathrm{C} 1$, three cases between cluster $\mathrm{C} 0$ and $\mathrm{C} 2$, and one case between $\mathrm{C} 1$ and $\mathrm{C} 2$. Figure 12 shows the daily-mean SLP, horizontal wind, and equivalent potential temperature at $850 \mathrm{hPa}$ for the four transition events between cluster $\mathrm{C} 0$ and $\mathrm{C} 1$. Stationary LLJs that are due to the baiu front and southwesterly flow along the North Pacific subtropical high exist in both cluster $\mathrm{C} 0$ and cluster $\mathrm{C} 1$. Moreover, cluster $\mathrm{C} 0$ is also characterized by the passage of a meso- $\alpha$-scale cyclone around Kyushu (Figs. 12c,f,i), which may transport more moisture to Kyushu than is associated with cluster $\mathrm{C} 1$ (Figs. 12b,d,e,g,h). Cluster C0 on 10 July 2009 (Fig. 12a) is characterized by the confluence of the LLJ due to the baiu front and cyclonic circulation located around $20^{\circ} \mathrm{N}, 132^{\circ} \mathrm{E}$, which may transport more moisture in comparison with cluster C1 on 11 July 2009.

Three transition events between cluster $\mathrm{C} 0$ and $\mathrm{C} 2$ are characterized by strong cyclonic circulation due to the typhoon (Fig. 13). Although Figs. 13b, 13d, and 13f are classified as cluster $\mathrm{C} 0$ with $\mathrm{SOM}$, all of these dates are obviously a typhoon pattern located around the northwest sea of Kyushu. SOM classified this case into $\mathrm{C} 0$ despite the fact that the heavy rainfall days are much influenced by a typhoon (Figs. 13b,d,f). This kind of classification with SOM is also found in transition between $\mathrm{C} 1$ and $\mathrm{C} 2$ (Fig. 14). On 18 July 2012, a typhoon located around $33^{\circ} \mathrm{N}, 125^{\circ} \mathrm{E}$ transported moisture into Kyushu (Fig. 14a) and it moved northward on 19 July 2012 (Fig. 14b). On 19 July 2012, the advection of moisture into Kyushu seemed to be influenced by both typhoon circulation and southwesterly flow along the western fringe of the North Pacific subtropical high (Fig. 14b). As described above, the SOM analysis did not always lead to a result that is consistent with the intuition of synopticians, especially in a case in which a typhoon resides at a different location from the position where a cluster points.

\section{b. Sensitivity tests}

We here check the node-number dependency in SOM. Table 2 shows the mean differences of rainfall duration (DDS minus RA-S) in all rainfall events of the heavy rainfall days over Kyushu in different SOM 
(a) JRA SLP UV850 Thetae850 C0 20090710

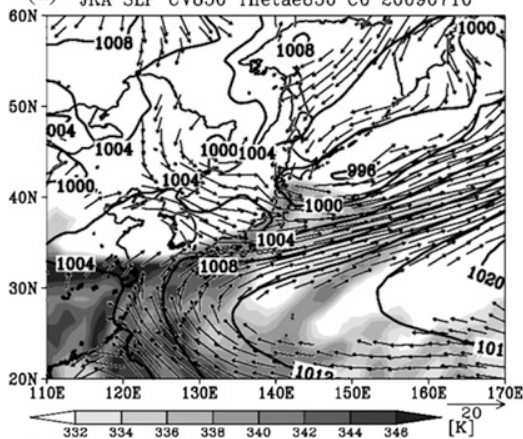

(c) JRA SLP UV850 Thetae850 C0 20090725

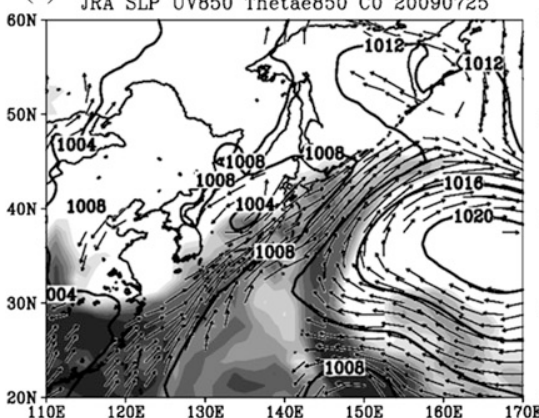

(e)

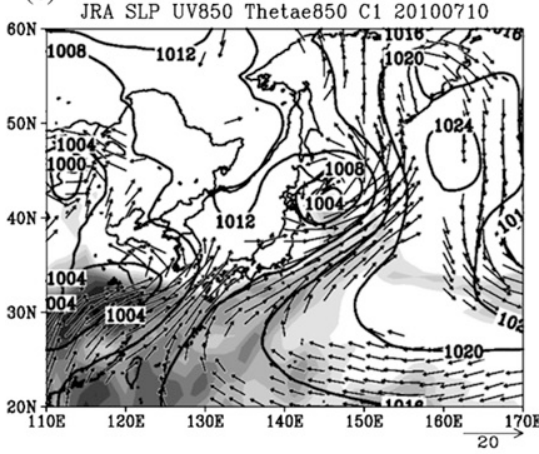

(h) JRA SLP UV850 Thetae850 C1 20140702

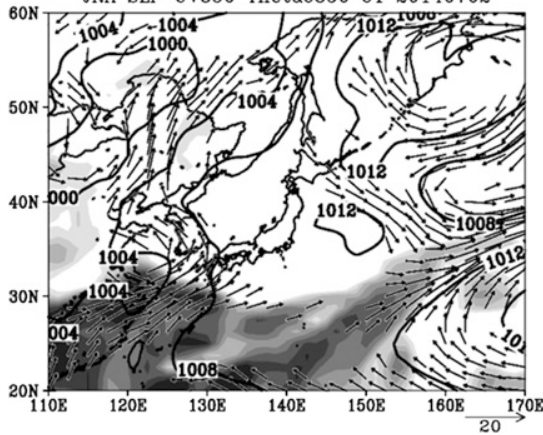

(b) JRA SLP UV850 Thetae850 C1 20090711

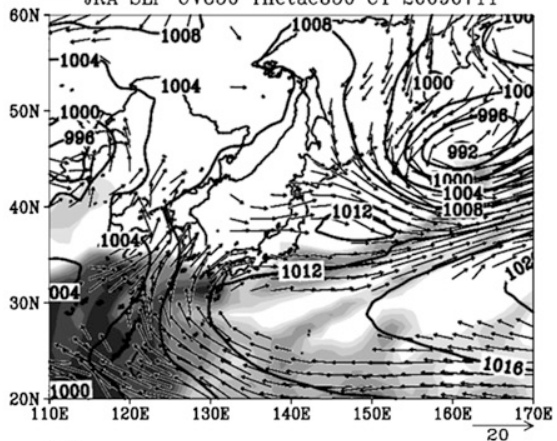

(d) JRA SLP UV850 Thetae850 C1 20090726

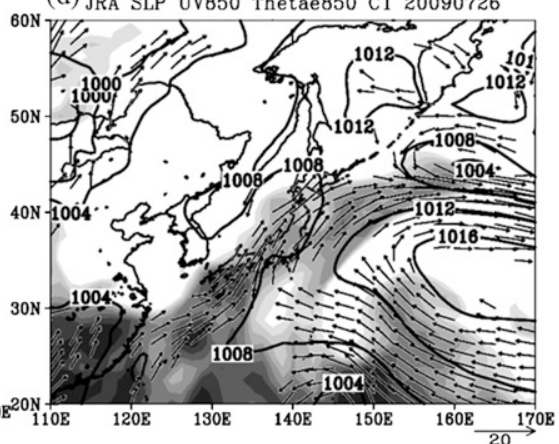

(f) JRA SLP UV850 Thetae850 C0 20100711

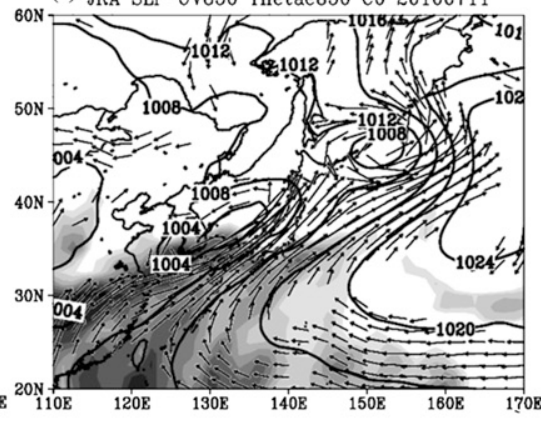

(g) JRA SLP UV850 Thetae850 C1 20100712

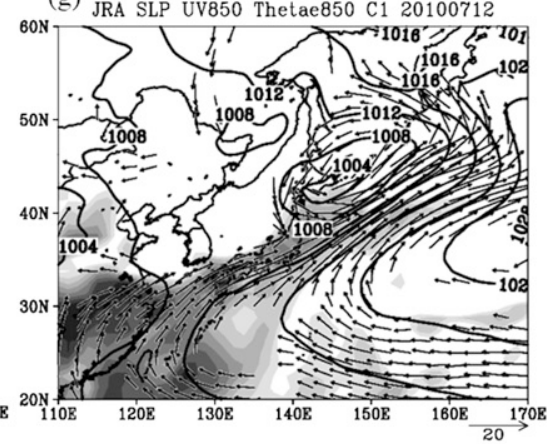

(i)

JRA SLP UV850 Thetae850 C0 20140703

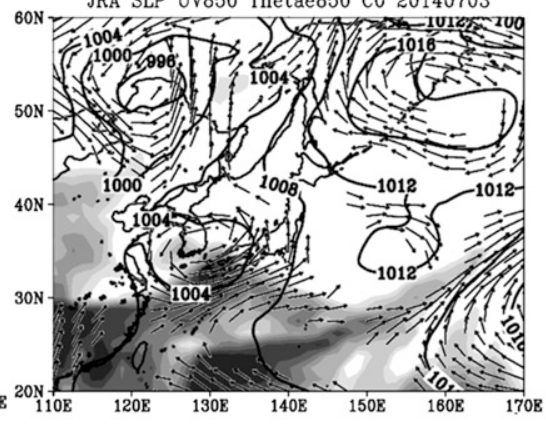

FIG. 12. Daily mean SLP (contours; interval is $4 \mathrm{hPa}$ ), 850-hPa equivalent potential temperature (shading; $\mathrm{K}$ ), and 850-hPa horizontal wind (vectors; $\mathrm{m} \mathrm{s}^{-1}$ ) during four transition events between cluster $\mathrm{C} 0$ and $\mathrm{C} 1$ from JRA-55 reanalysis data. The shading scale and the unit vector of $20 \mathrm{~m} \mathrm{~s}^{-1}$ are at the bottom of (a), and vectors of $<5 \mathrm{~m} \mathrm{~s}^{-1}$ are omitted. 
(a) JRA SLP UV850 Thetae850 C2 20120827

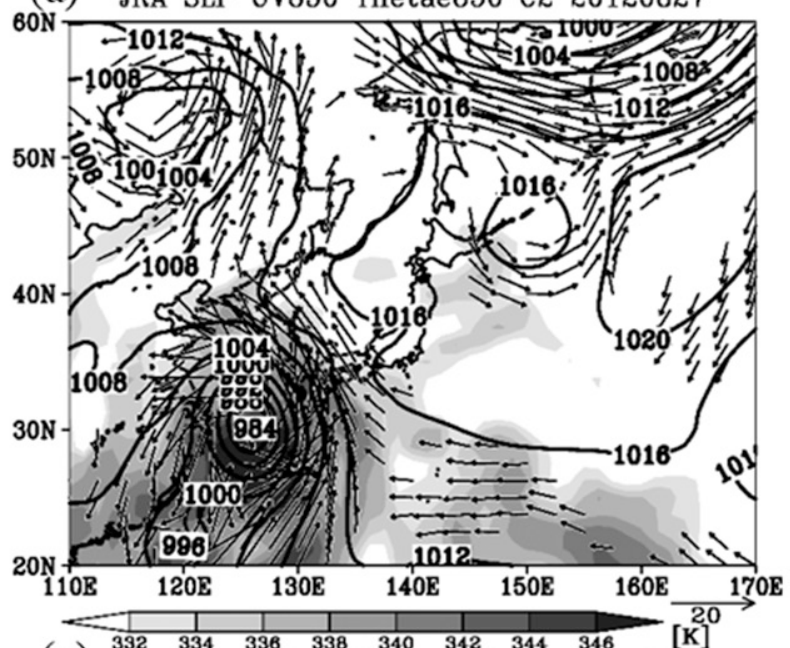

$\begin{array}{llllllll}\text { (c) }{ }_{\text {JRA S2 }}^{334} & 338 & 338 & 340 & 342 & 344 & 346 & \text { [K] }\end{array}$

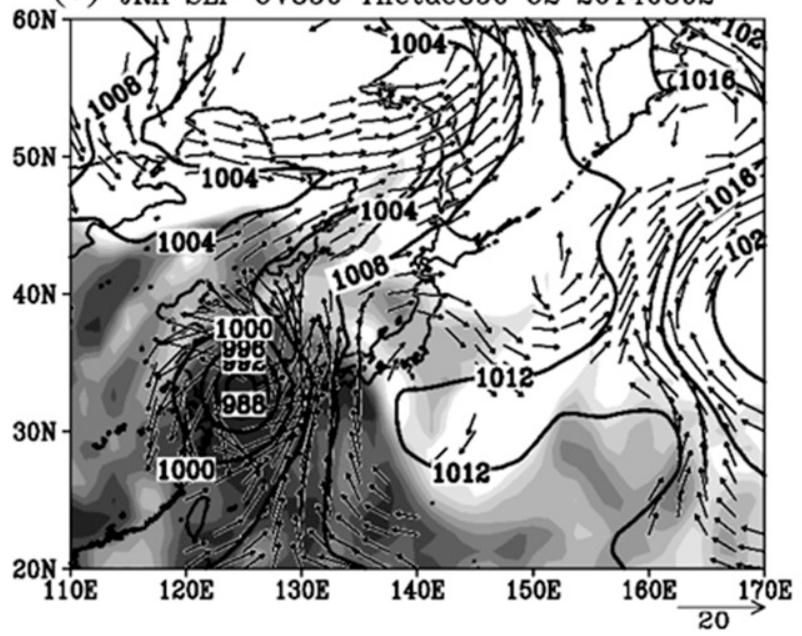

60N (e) JRA SLP UV850 Thetae850 C2 20150711

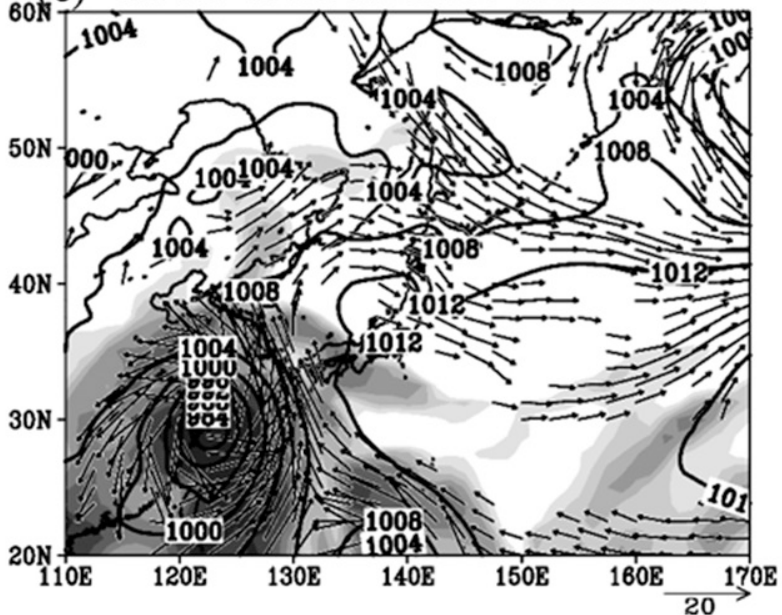

(b) JRA SLP UV850 Thetae850 C0 20120828

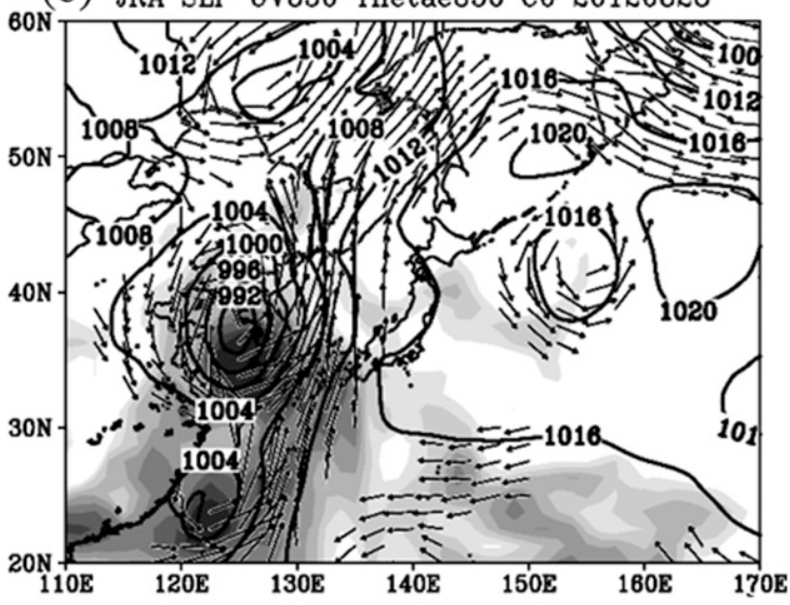

(d) JRA SLP UV850 Thetae850 C0 20140803

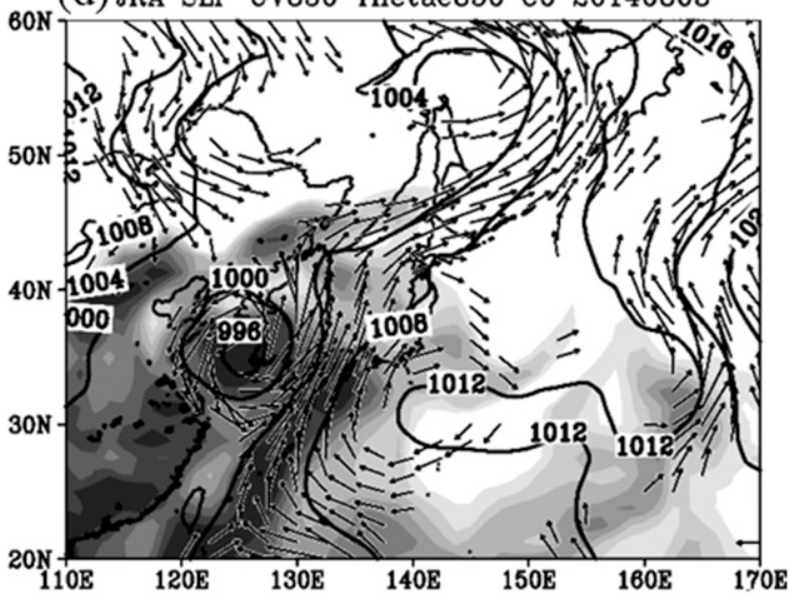

(f) JRA SLP UV850 Thetae850 C0 20150712

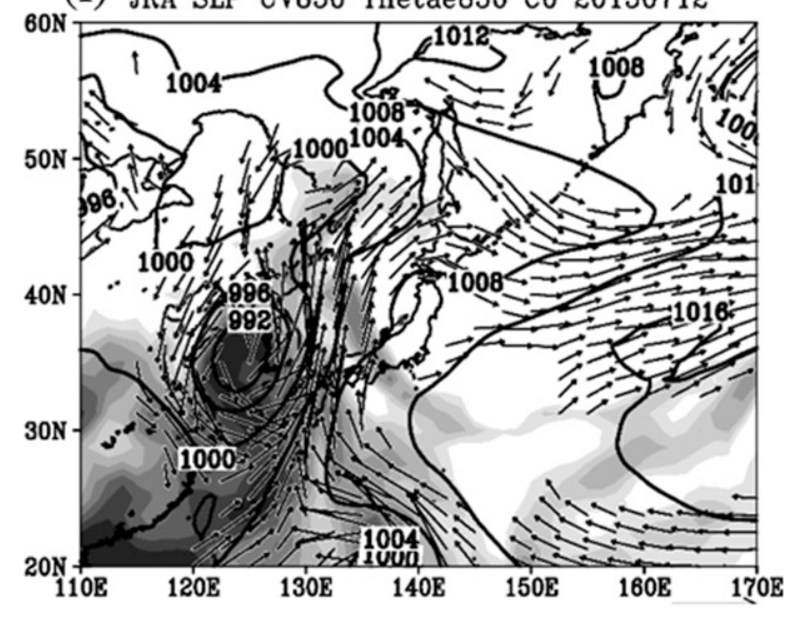

FIG. 13. As in Fig. 12, but for three transition events between cluster $\mathrm{C} 0$ and $\mathrm{C} 2$. 
(a) JRA SLP UV850 Thetae850 C2 20120718

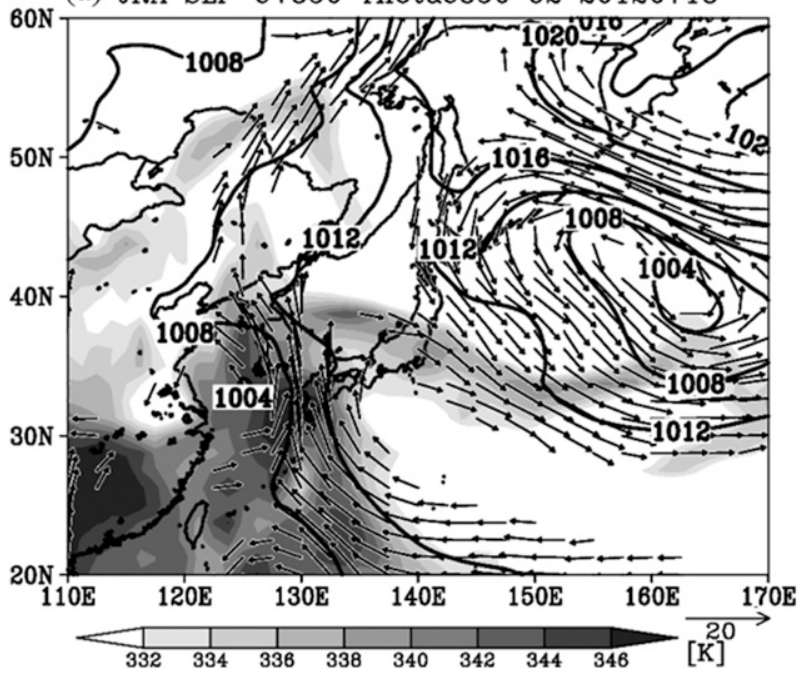

(b) JRA SLP UV850 Thetae850 C1 20120719

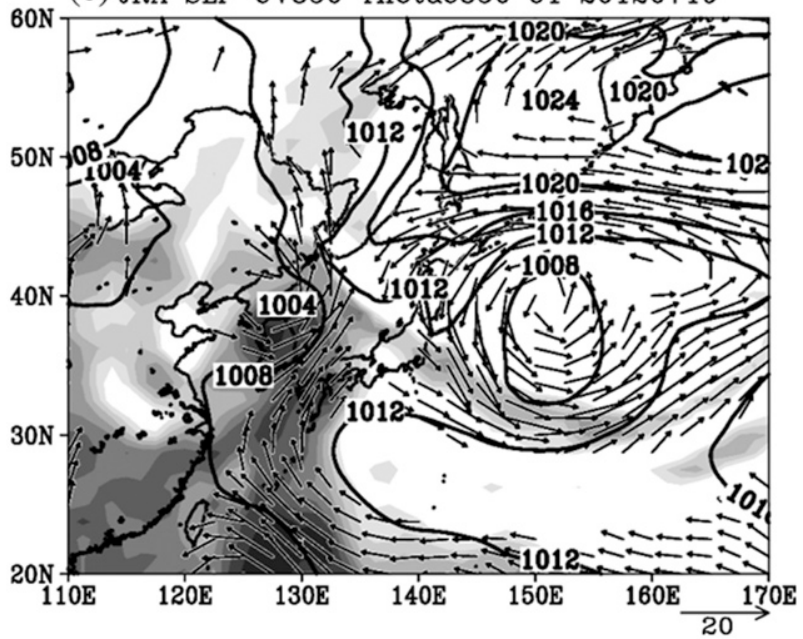

FIG. 14. As in Fig. 12, but for one transition event between cluster $\mathrm{C} 1$ and $\mathrm{C} 2$.

experiments as the node number changes from $6 \times 6$ to $12 \times 12$. Almost all of the experiments objectively classify the synoptic patterns related to heavy rainfall, similar to patterns with a node number of $10 \times 10$ (not shown). However, SOM with a node number of $9 \times 9$ provided a different cluster set. Clusters $\mathrm{C} 0$ and $\mathrm{C} 2$ (Figs. 15a,e) in the $9 \times 9 \mathrm{SOM}$ are the same as the standard setting (Figs. 5a,e), but the composite pattern for cluster $\mathrm{C} 1$ in the $9 \times 9 \mathrm{SOM}$ also shows a typhoon pattern that brings heavy rainfall to western Kyushu (Figs. 15c,d). The mean differences in rainfall duration in cluster $\mathrm{C} 2$ are higher than in the other clusters in almost all experiments, although the DDS has a negative bias of $3.2 \mathrm{~h}$ with a node number of $9 \times 9$ and $1.0 \mathrm{~h}$ with a node number of $8 \times 8$. In cluster $\mathrm{C} 2$, large positive biases are also evident in rainfall events with a peak value over $30 \mathrm{~mm} \mathrm{~h}^{-1}$, except experiments with node numbers of $8 \times 8$ and $9 \times 9$ (not shown). Therefore, the nodenumber dependency has little effect on the results in this paper.

We next discuss the area coverage dependency on the definition of heavy rainfall days. Table 3 shows the mean bias of rainfall duration in all rainfall events of the heavy rainfall days in different SOM experiments with area coverages ranging from $5 \%$ to $40 \%$. The node number is fixed as $10 \times 10$. All of the sensitivity experiments objectively classify synoptic patterns relative to the standard setting (not shown). Rainfall duration biases are higher in cluster $\mathrm{C} 2$ than in other clusters for area coverages of $5 \%, 10 \%$, and $25 \%$, whereas cluster $\mathrm{C} 0$ has higher positive biases than cluster $\mathrm{C} 2$ for area coverages of $15 \%, 20 \%$, and $30 \%-40 \%$. In contrast, for rainfall events for which the peak value exceeds $30 \mathrm{~mm} \mathrm{~h}^{-1}$, rainfall duration bias in cluster $\mathrm{C} 2$ has a large long-standing bias ranging from +6.4 to $+26.2 \mathrm{~h}$ within the area coverage from $5 \%$ to $25 \%$, whereas the cluster $\mathrm{C} 0$ has a negative duration bias ranging from -4.1 to $-0.5 \mathrm{~h}$ (Table 4 ).

The sensitivity of threshold for heavy rainfall day is moreover marked. Table 5 shows the mean difference of rainfall duration (DDS minus RA-S) in all rainfall events of heavy rainfall days among the different threshold $\left(\mathrm{mm} \mathrm{day}{ }^{-1}\right)$ for heavy rainfall days. Here the other settings are the same as in the standard experiment. All of the sensitivity experiments objectively classify synoptic patterns into strong monsoons, weak monsoons, and typhoons (not shown). The experiment with a threshold of $10 \mathrm{~mm}$ day $^{-1}$ shows more positive bias than is associated with the standard experiment in clusters $\mathrm{C} 1$ and $\mathrm{C} 2$. On the other hand, the experiment with a threshold of $50 \mathrm{~mm}$ day $^{-1}$ shows a negative bias of $0.4 \mathrm{~h}$ in cluster $\mathrm{C} 1$, and the positive bias in cluster $\mathrm{C} 2$ is smaller than that of the experiments with thresholds of 10 and $30 \mathrm{~mm}$ day $^{-1}$. A positive bias in cluster $\mathrm{C} 2$ is also evident in rainfall events with a peak value over $30 \mathrm{~mm} \mathrm{~h}^{-1}$ (Table 6). The amount of positive duration bias is $+4.9 \mathrm{~h}$ in the case of a

TABLE 2. The mean difference (h) of rainfall duration (DDS minus RA-S) in all rainfall events of heavy rainfall days excluding transition days among different node numbers. Here the standard experiment in this study is the node number with $10 \times 10$.

\begin{tabular}{cccccccc}
\hline $\begin{array}{c}\text { Node } \\
\text { no. }\end{array}$ & $6 \times 6$ & $7 \times 7$ & $8 \times 8$ & $9 \times 9$ & $10 \times 10$ & $11 \times 11$ & $12 \times 12$ \\
\hline $\mathrm{C} 0$ & +1.1 & +1.1 & +1.3 & +1.0 & +1.3 & +1.4 & +1.4 \\
$\mathrm{C} 1$ & +0.3 & +0.4 & -0.2 & +3.2 & 0.0 & 0.0 & +0.3 \\
$\mathrm{C} 2$ & +1.0 & +0.9 & -1.0 & -3.2 & +1.1 & +1.0 & +2.7 \\
\hline
\end{tabular}


(a) Composite SLP EPT850 U850 V850 C0

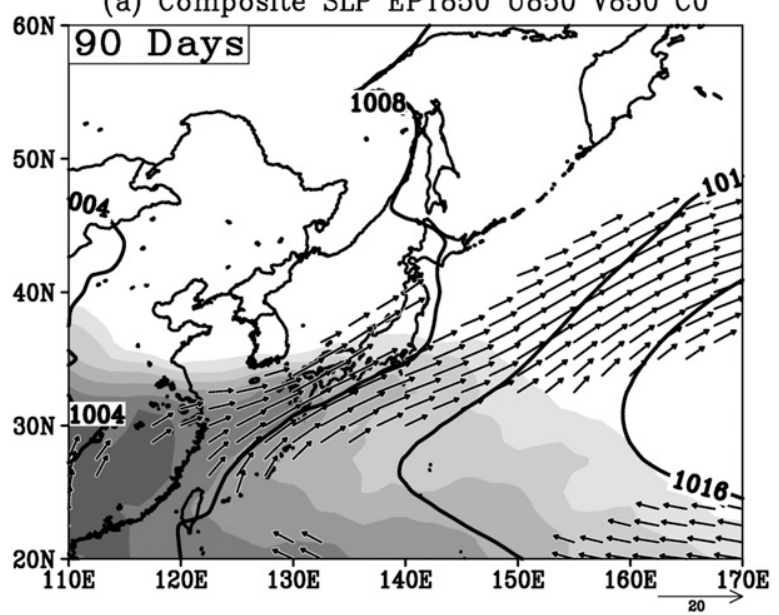

(c) Composite SLP EPT850 U850 V850 C1

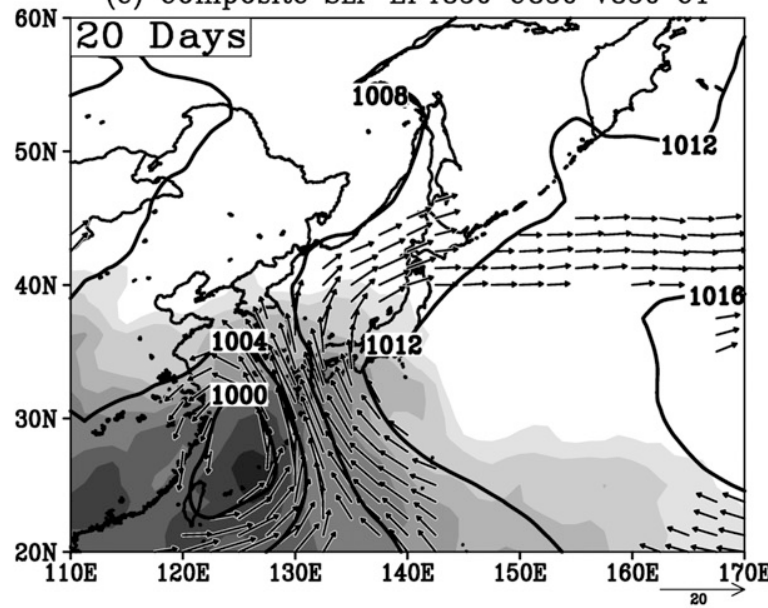

(e) Composite SLP EPT850 U850 V850 C2

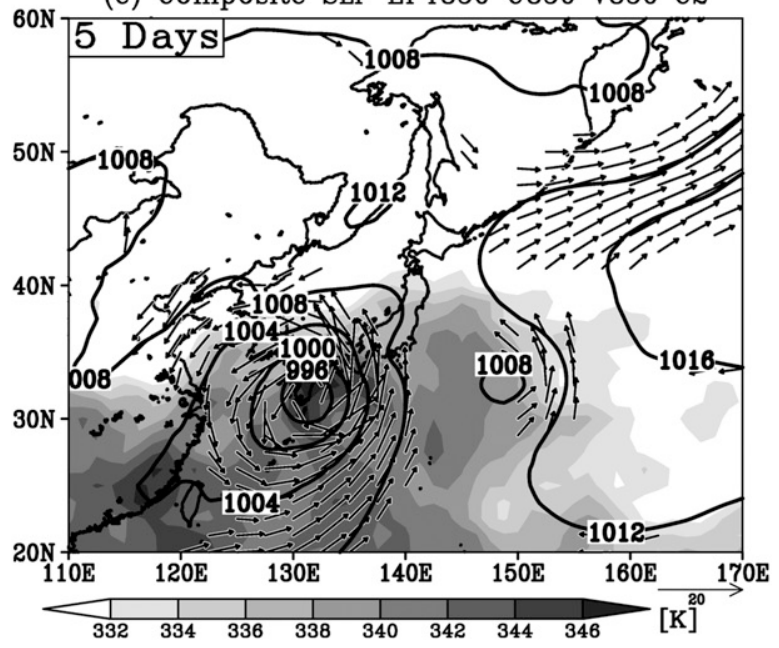

(b) Composite Rainfall RA-S C0

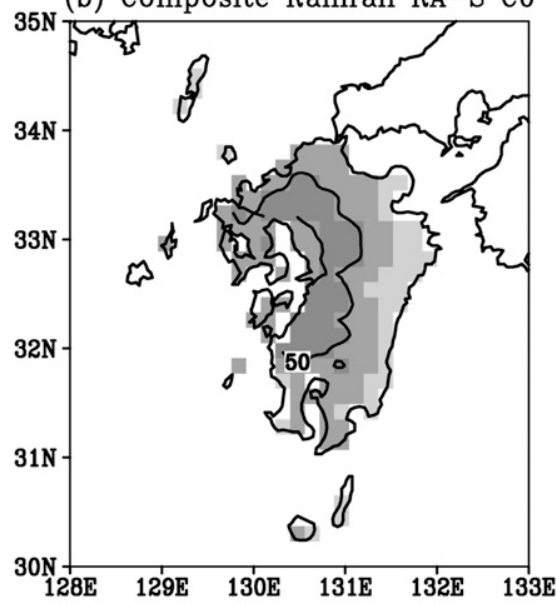

(d) Composite Rainfall RA-S C1

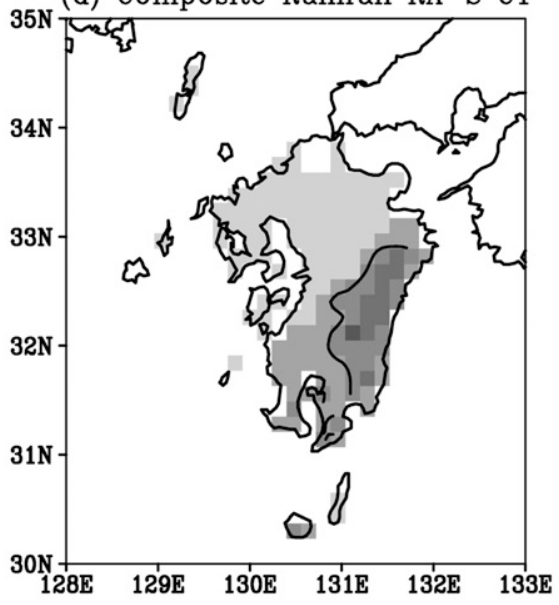

(f) Composite Rainfall RA-S C2

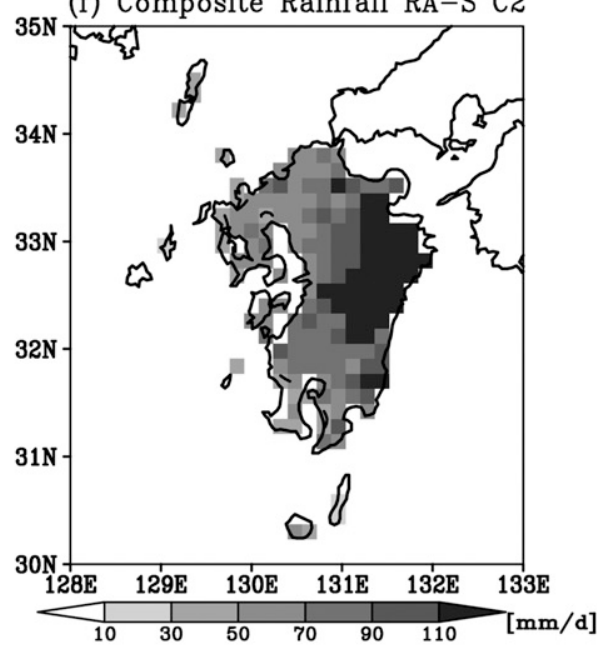

FIG. 15. As in Fig. 5, but for the node number of $9 \times 9$ for SOM. 
TABLE 3. The mean difference (h) of rainfall duration (DDS minus RA-S) in all rainfall events of heavy rainfall days excluding transition days among different area coverages with the node number of $10 \times 10$. Here the standard experiment in this study is the area coverage with $20 \%$.

\begin{tabular}{ccccccccc}
\hline $\begin{array}{c}\text { Area coverage } \\
(\%)\end{array}$ & 5 & 10 & 15 & 20 & 25 & 30 & 35 & 40 \\
\hline $\mathrm{C} 0$ & +1.7 & +1.5 & +1.5 & +1.3 & +1.0 & +1.1 & +1.0 & +1.0 \\
$\mathrm{C} 1$ & +0.4 & +0.7 & +0.1 & 0.0 & -0.3 & -0.1 & -0.1 & -0.8 \\
$\mathrm{C} 2$ & +2.5 & +1.8 & +0.9 & +1.1 & +2.9 & -1.0 & +0.4 & +0.4 \\
\hline
\end{tabular}

threshold of $10 \mathrm{~mm} \mathrm{day}^{-1}$ (Table 6). The threshold of $30 \mathrm{~mm} \mathrm{~h}^{-1}$ is therefore one of the reasonable values to keep enough events for some statistics for every cluster.

\section{c. Model biases}

This study provided the precipitation bias information with the RAM results with $15-\mathrm{km}$ horizontal resolution. Heavy rainfall in Kyushu is mainly attributed to orographic precipitation associated with the low-level wind. We speculate that the smoothed topography of RAM with a resolution of $15 \mathrm{~km}$ may weaken the convection, which could lead to a positive rainfall duration bias. In addition, the rainfall intensity and duration in mesoscale-convective systems are controlled by the interaction between vertical wind shear and the cold pool (Rotunno et al. 1988) and by local low-level wind convergence from convective heating (Kato and Goda 2001 ), for which the spatial scale is meso- $\beta$ scale or smaller. The model resolution of $15 \mathrm{~km}$ that we used may be insufficient to reproduce these mesoscale environmental fields accurately. This was shown in the total precipitation amount in the DDS (Fig. 6) in comparison with the observation (Fig. 5). Note, however, that the typhoon in the DDS was well reproduced in terms of its position. Figure 16 shows the location of 22 typhoon centers associated with cluster $\mathrm{C} 2$, using capital letters for JRA-55 and the lowercase letters for DDS. Here the typhoon center is defined as the minimum value of SLP. The average of the difference of center of typhoon between DDS and JRA-55 is $207.0 \mathrm{~km}$. The minimum distance is $18.4 \mathrm{~km}$ (label E/e) and the maximum distance is $665.7 \mathrm{~km}$ (label A/a).

The frequency of rainfall events in the DDS is also a problem. We obtained 42286 events in the RA output and 13840 events in the DDS output (Figs. 3d,e). The causes of this difference are speculated to be that the NHM with $15-\mathrm{km}$ resolution did not reproduce mesoscale convective systems well and then several rainfall events detected in RA are possibly counted as a single event in NHM because of the nonzero precipitation bias. This means that the rainfall duration bias
TABLE 4. The mean difference (h) of rainfall duration (DDS minus RA-S) in the rainfall events excluding transition days for which the peak value exceeds $30 \mathrm{~mm} \mathrm{~h}^{-1}$ among different area coverages with the node number of $10 \times 10$. Dashes in the table indicate cases in which the number of rainfall events with a peak value over $30 \mathrm{~mm} \mathrm{~h}^{-1}$ is less than 10 events for either DDS or RA-S. Here the standard experiment in this study is the area coverage with $20 \%$.

\begin{tabular}{ccccccccc}
\hline $\begin{array}{c}\text { Area coverage } \\
(\%)\end{array}$ & 5 & 10 & 15 & 20 & 25 & 30 & 35 & 40 \\
\hline $\mathrm{C} 0$ & -0.43 & -2.7 & -0.5 & -2.1 & -4.1 & -3.3 & - & - \\
$\mathrm{C} 1$ & - & - & - & - & - & - & - & - \\
$\mathrm{C} 2$ & +6.4 & +25.7 & +26.2 & +26.2 & +22.5 & - & - & - \\
\hline
\end{tabular}

could not be perfectly corrected with conventional methods such as quantile mapping or shifting and scaling because they are unable to correct the number of dry days.

The bias correction of rainfall amount and frequency is crucial for hydrological applications. Precipitation intensity and frequency are related to frequency of precipitation types including stratiform/ convective precipitation and drizzle. It is necessary to examine the precipitation frequency and intensity, and not only duration, to evaluate accurately the rainfall bias in the DDS when considering precipitation characteristics (Dai 2006). While the shifting and scaling and quantile mapping are generally applied to the daily or monthly data (e.g., Bordoy and Burlando 2013; Lafon et al. 2013), no one has proposed a reasonable way to correct the precipitation intensity with hourly time scales. Hence there is still an open question as to how to correct the precipitation intensity. On the other hand, as described in the introduction, the rainfall duration bias would also be another important problem when we estimate the timing and amount of direct runoff peak in a catchment. The shifting and scaling method and quantile mapping method could possibly lead to an imprecise impact assessment, even if the total precipitation amount is exactly corrected; they work as if a stratiform-type rainfall event characterized by prolonged moderate rainfall changed to a long-standing convective-type rainfall event.

TABLE 5. The mean difference (h) of rainfall duration (DDS minus RA-S) in all rainfall events of heavy rainfall days excluding transition days among the different thresholds $\left(\mathrm{mm} \mathrm{day}^{-1}\right)$ for heavy rainfall days. Here the standard experiment in this study is the threshold with $30 \mathrm{~mm}_{\text {day }}{ }^{-1}$.

\begin{tabular}{ccrc}
\hline \hline Threshold (mm day & \\
& & & \\
& 10 & 30 & 50 \\
\hline C0 & +0.9 & +1.3 & +1.1 \\
C1 & +1.6 & 0.0 & -0.4 \\
C2 & +2.6 & +1.1 & +0.4 \\
\hline
\end{tabular}


TABLE 6. The mean difference (h) of rainfall duration (DDS minus RA-S) in the rainfall events excluding transition days for which the peak value exceeds $30 \mathrm{~mm} \mathrm{~h}^{-1}$ among different thresholds with the node number of $10 \times 10$. Dashes in the table indicate cases in which the number of rainfall events with a peak value over $30 \mathrm{~mm} \mathrm{~h}^{-1}$ is less than 10 events for either DDS or RA-S. Here the standard experiment in this study is the threshold with $30 \mathrm{~mm} \mathrm{day}^{-1}$.

\begin{tabular}{cccc}
\hline \hline Threshold $\left(\mathrm{mm} \mathrm{day}^{-1}\right)$ & 10 & 30 & 50 \\
\hline C0 & - & -2.1 & -0.8 \\
C1 & -3.8 & - & - \\
C2 & +4.9 & +26.2 & - \\
\hline
\end{tabular}

The spatial and time scales in stratiform and convective precipitation may contribute to the surface runoff or infiltration processes. For example, Toews et al. (2009) classified convective and stratiform precipitation on the basis of daily precipitation data by focusing on the difference of spatial scales; and they suggested that stratiform precipitation has much more impact on groundwater recharge rather than convective precipitation. On the other hand, we have emphasized the difference of time scale between stratiform and convective precipitation. If one thought of precipitation events with the same precipitation amount, the duration time would be a key agent in evaluating the surfacerunoff and infiltration processes. We will refer this matter to a future paper.

\section{Conclusions}

We have investigated the rainfall duration bias with a RAM over Kyushu in July and August from 2006 to 2015. The results showed that the DDS provided a dry bias (Fig. 3) and a long-standing rainfall bias, especially over eastern Kyushu and in part of the northwest in Kyushu (Fig. 4c). The rainfall bias was emphasized for rainfall events with a strong rainfall peak (Fig. 4f). Using SOM and the $K$-means method, we objectively extracted three typical clusters of synoptic patterns related to heavy rainfall days: strong monsoons, weak monsoons, and typhoons (Fig. 5). The cluster analysis clarified that the model bias of rainfall duration depended on the synoptic patterns. The long-standing biases were in western Kyushu under the strong monsoon environment and in southern and east-coast Kyushu when a typhoon approaches from the south (Fig. 8). The typhoon bias was related to a strong rainfall peak in rainfall events (Fig. 11b).

A possible approach to correct the rainfall duration bias would be to scale rainfall durations uniformly for all rainfall events for the model output so that the mean of rainfall durations for the model would match that for the

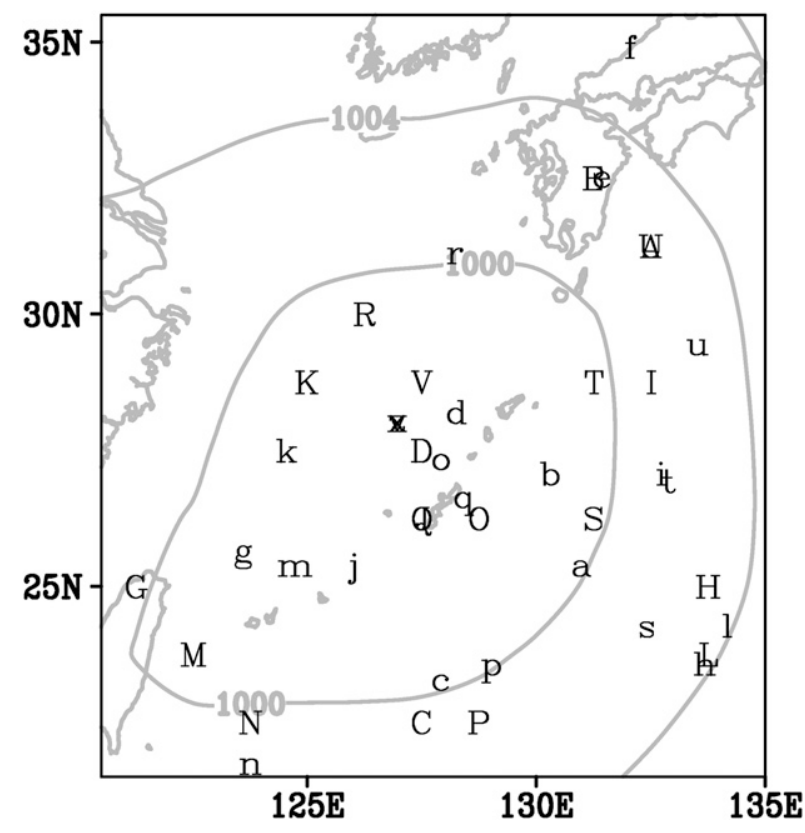

FIG. 16. Locations of typhoon centers in cluster C2 with JRA-55 (capital letters) and DDS (lowercase letters). Here the typhoon center is defined as the minimum value of SLP. The gray contours show the cluster-composite SLP (hPa) for JRA-55 in cluster C2.

observations. For example, for a positive duration bias, we could cut the rainfall days from an event and equally distribute the removed amount to the remaining rainfall. It is beyond the scope of this paper to propose a feasible method for bias correction of rainfall duration, however.

Acknowledgments. We thank Prof. M. Nakatsugawa, Dr. T. Sato, Prof. S. Minobe, and Dr. Y. N. Sasaki for giving us insightful comments. The JMA/MRI-NHM and JRA-55 reanalysis data were used with permission of the JMA. This study is supported by the Social Implementation Program on Climate Change Adaptation Technology project of the Ministry of Education, Culture, Sports, Science and Technology of Japan. The DDS was performed by using the Hokkaido University High-Performance Computing System. Figures were drawn using Grid Analysis and Display System and Matplotlib.

\section{REFERENCES}

Akiyama, T., 1973: The large-scale aspects of the characteristic features of the baiu front with special emphasis on the relation among the ageostrophic low-level jet stream, moist tongue, convective warming, convergence zone within baiu front and heavy rainfall. Pap. Meteor. Geophys., 24, 157-188, https://doi.org/ 10.2467/mripapers1950.24.2_157.

Bartholy, J., and R. Pongrácz, 2007: Regional analysis of extreme temperature and precipitation indices for the Carpathian 
Basin from 1946 to 2001. Global Planet. Change, 57, 83-95, https://doi.org/10.1016/j.gloplacha.2006.11.002.

Berg, P., H. Feldmann, and H.-J. Panitz, 2012: Bias correction of high resolution regional climate model data. J. Hydrol., 448449, 80-92, https://doi.org/10.1016/j.jhydrol.2012.04.026.

Bordoy, R., and P. Burlando, 2013: Bias correction of regional climate model simulations in a region of complex orography. J. Appl. Meteor. Climatol., 52, 82-101, https://doi.org/10.1175/ JAMC-D-11-0149.1.

Christensen, J. H., F. Boberg, O. B. Christensen, and P. LucasPicher, 2008: On the need for bias correction of regional climate change projections of temperature and precipitation. Geophys. Res. Lett., 35, L20709, https://doi.org/10.1029/ 2008 GL035694.

Dai, A., 2006: Precipitation characteristics in eighteen coupled climate models. J. Climate, 19, 4605-4630, https://doi.org/ 10.1175/JCLI3884.1.

DeGaetano, A. T., 2009: Time-dependent changes in extremeprecipitation return-period amounts in the continental United States. J. Appl. Meteor. Climatol., 48, 2086-2099, https:// doi.org/10.1175/2009JAMC2179.1.

Donat, M. G., A. L. Lowry, L. V. Alexander, P. A. O'Gorman, and N. Maher, 2016: More extreme precipitation in the world's dry and wet regions. Nat. Climate Change, 6, 508-513, https:// doi.org/10.1038/nclimate2941.

Ehret, U., E. Zehe, V. Wulfmeyer, K. Warrach-Sagi, and J. Liebert, 2012: HESS opinions "Should we apply bias correction to global and regional climate model data?" Hydrol. Earth Syst. Sci., 16, 3391-3404, https://doi.org/10.5194/hess-16-33912012.

Fujibe, F., K. Saito, D. S. Wratt, and S. G. Bradley, 1999: A numerical study on the diurnal variation of low-level wind in the lee of a two-dimensional mountain. J. Meteor. Soc. Japan, 77, 827-843, https://doi.org/10.2151/jmsj1965.77.4_827.

__, N. Yamazaki, and K. Kobayashi, 2006: Long-term changes of heavy precipitation and dry weather in Japan (1901-2004). J. Meteor. Soc. Japan, 84, 1033-1046, https://doi.org/10.2151/ jmsj.84.1033.

Giorgi, F., 1990: Simulation of regional climate using a limited area model nested in a general circulation model. J. Climate, 3, 941-963, https://doi.org/10.1175/1520-0442(1990)0030941: SORCUA2.0.CO;2.

Iida, Y., K. Okamoto, T. Ushio, and R. Oki, 2006: Simulation of sampling error of average rainfall rates in space and time by five satellites using radar-AMeDAS composites. Geophys. Res. Lett., 33, L01816, https://doi.org/10.1029/2005GL024910.

Ikawa, M., and K. Saito, 1991: Description of a nonhydrostatic model developed at the forecast research department of the MRI. MRI Tech. Rep. 28, 238 pp.

Ines, A. V. M., and J. W. Hansen, 2006: Bias correction of daily GCM rainfall for crop simulation studies. Agric. For. Meteor., 138, 44-53, https://doi.org/10.1016/j.agrformet.2006.03.009.

Kain, J. S., and J. M. Fritsch, 1993: Convective parameterization for mesoscale models: The Kain-Fritsch scheme. The Representation of Cumulus Convection in Numerical Models, Meteor. Monogr., No. 46, Amer. Meteor. Soc., 165-170.

Kato, T., and H. Goda, 2001: Formation and maintenance processes of a stationary band-shaped heavy rainfall observed in Niigata on 4 August 1998. J. Meteor. Soc. Japan, 79, 899-924, https://doi.org/10.2151/jmsj.79.899.

Kobayashi, S., and Coauthors, 2015: The JRA-55 Reanalysis: General specifications and basic characteristics. J. Meteor. Soc. Japan, 93, 5-48, https://doi.org/10.2151/jmsj.2015-001.
Kodama, Y., 1992: Large-scale common features of subtropical precipitation zones (the baiu frontal zone, the SPCZ, and the SACZ). Part I: Characteristics of subtropical frontal zones. J. Meteor. Soc. Japan, 70, 813-836, https://doi.org/10.2151/ jmsj1965.70.4_813.

Kohonen, T., 1982: Self-organized formation of topologically correct feature maps. Biol. Cybern., 43, 59-69, https://doi.org/ 10.1007/BF00337288.

Kumagai, Y., 2004a: Implementation of a non-local like PBL scheme in JMANHM. CAS/JSC WGNE Research Activities in Atmospheric and Oceanic Modelling Rep. 34, 417-418.

2004b: Improvement of the land surface processes in JMANHM. CAS/JSC WGNE Research Activities in Atmospheric and Oceanic Modelling Rep. 34, 419-420.

Lafon, T., S. Dadson, G. Buys, and C. Prudhomme, 2013: Bias correction of daily precipitation simulated by a regional climate model: A comparison of methods. Int. J. Climatol., 33, 1367-1381, https://doi.org/10.1002/joc.3518.

Lall, U., B. Rajagopalan, and D. G. Tarboton, 1996: A nonparametric wet/dry spell model for resampling daily precipitation. Water Resour. Res., 32, 2803-2823, https://doi.org/10.1029/ 96WR00565.

Leander, R., and T. A. Buishand, 2007: Resampling of regional climate model output for the simulation of extreme river flows. J. Hydrol., 332, 487-496, https://doi.org/10.1016/j.jhydrol.2006.08.006.

Li, J., A. Sharma, J. Evans, and F. Johnson, 2018: Addressing the mischaracterization of extreme rainfall in regional climate model simulations-A synoptic pattern based bias correction approach. J. Hydrol., 556, 901-912, https://doi.org/10.1016/ j.jhydrol.2016.04.070.

Maraun, D., 2012: Nonstationarities of regional climate model biases in European seasonal mean temperature and precipitation sums. Geophys. Res. Lett., 39, L06706, https://doi.org/ 10.1029/2012GL051210.

, 2013: Bias correction, quantile mapping, and downscaling: Revisiting the inflation issue. J. Climate, 26, 2137-2143, https:// doi.org/10.1175/JCLI-D-12-00821.1.

_ precipitation intensity: Improved early data, error estimates and an update from 2000 to 2006. Int. J. Climatol., 28, 833-842, https://doi.org/10.1002/joc.1672.

— mate change: Recent developments to bridge the gap between dynamical models and the end user. Rev. Geophys., 48, RG3003, https://doi.org/10.1029/2009RG000314.

Matsumoto, S., 1972: Unbalanced low-level jet and solenoidal circulation associated with heavy rainfalls. J. Meteor. Soc. Japan, 50, 194-203, https://doi.org/10.2151/jmsj1965.50.3_194.

Nagata, K., 2011: Quantitative precipitation estimation and quantitative precipitation forecasting by the Japan Meteorological Agency. RSMC Tokyo-Typhoon Center Tech. Rev. 13, 37-50, http://www.jma.go.jp/jma/jma-eng/jma-center/rsmc-hp-pub-eg/ techrev/text13-2.pdf.

Nguyen-Le, D., T. J. Yamada, and D. Tran-Anh, 2017: Classification and forecast of heavy rainfall in northern Kyushu during baiu season using weather pattern recognition. Atmos. Sci. Lett., 18, 324-329, https://doi.org/10.1002/asl.759.

Ninomiya, K., 1984: Characteristics of baiu front as a predominant subtropical front in the summer Northern Hemisphere. J. Meteor. Soc. Japan, 62, 880-894, https://doi.org/10.2151/ jmsj1965.62.6_880.

, 2000: Large- and meso- $\alpha$-scale characteristics of meiyu/baiu front associated with intense rainfalls in 1-10 July 1991. 
J. Meteor. Soc. Japan, 78, 141-157, fhttps://doi.org/10.2151/ jmsj1965.78.2_141.

_, and T. Akiyama, 1992: Multi-scale features of baiu, the summer monsoon over Japan and the east Asia. J. Meteor. Soc. Japan, 70, 467-495, https://doi.org/10.2151/jmsj1965.70.1B_467.

— baiu front and associated precipitation systems. J. Meteor. Soc. Japan, 85B, 103-122, https://doi.org/10.2151/jmsj.85B.103.

Nishiyama, K., S. Endo, K. Jinno, C. B. Uvo, J. Olsson, and R. Berndtsson, 2007: Identification of typical synoptic patterns causing heavy rainfall in the rainy season in Japan by a selforganizing map. Atmos. Res., 83, 185-200, https://doi.org/ 10.1016/j.atmosres.2005.10.015.

Nyeko-Ogiramoi, P., P. Willems, G. Ngirane-Katashaya, and V. Ntegeka, 2012: Nonparametric statistical downscaling of precipitation from global climate models. Climate Models, L. Druyan, Ed., InTechOpen, 109-136, https://doi.org/10.5772/ 32910.

Ohba, M., S. Kadokura, Y. Yoshida, D. Nohara, and Y. Toyoda, 2015: Anomalous weather patterns in relation to heavy precipitation events in Japan during the baiu season. J. Hydrometeor., 16, 688-701, https://doi.org/10.1175/JHM-D14-0124.1.

, — - D. Nohara, and Y. Toyoda, 2016: Rainfall downscaling of weekly ensemble forecasts using self-organising maps. Tellus, 68A, 29293, https://doi.org/10.3402/tellusa.v68.29293.

Oki, R., and A. Sumi, 1994: Sampling simulation of TRMM rainfall estimation using Radar-AMeDAS composites. J. Appl. Meteor., 33, 1597-1608, https://doi.org/10.1175/1520-0450(1994) 0331597:SSOTRE2.0.CO;2.

Piani, C., J. O. Haerter, and E. Coppola, 2010: Statistical bias correction for daily precipitation in regional climate models over Europe. Theor. Appl. Climatol., 99, 187-192, https:// doi.org/10.1007/s00704-009-0134-9.

Prudhomme, C., N. Reynard, and S. Crooks, 2002: Downscaling of global climate models for flood frequency analysis: Where are we now? Hydrol. Processes, 16, 1137-1150, https://doi.org/ 10.1002/hyp.1054.

Pryor, S. C., J. A. Howe, and K. E. Kunkel, 2009: How spatially coherent and statistically robust are temporal changes in extreme precipitation in the contiguous USA? Int. J. Climatol., 29, 31-45, https://doi.org/10.1002/joc.1696.

Rajeevan, M., J. Bhate, and A. K. Jaswal, 2008: Analysis of variability and trends of extreme rainfall events over India using
104 years of gridded daily rainfall data. Geophys. Res. Lett., $\mathbf{3 5}$ L18707, https://doi.org/10.1029/2008GL035143; Corrigendum, 35, L23701, https://doi.org/10.1029/2008GL036105.

Rotunno, R., J. B. Klemp, and M. L. Weisman, 1988: A theory for strong, long-lived squall lines. J. Atmos. Sci., 45, 463-485, https:// doi.org/10.1175/1520-0469(1988)0450463:ATFSLL2.0.CO;2.

Saito, K., and J. Ishida, 2005: Implementation of the targeted moisture diffusion to JMA-NHM. CAS/JSC WGNE Research Activities in Atmospheric and Oceanic Modelling Rep. 35, 517-518.

—_ and Coauthors, 2006: The operational JMA nonhydrostatic mesoscale model. Mon. Wea. Rev., 134, 1266-1298, https:// doi.org/10.1175/MWR3120.1.

Sampe, T., and S.-P. Xie, 2010: Large-scale dynamics of the meiyu-baiu rainband: Environmental forcing by the westerly jet. J. Climate, 23, 113-134, https://doi.org/10.1175/ 2009JCLI3128.1.

Shabalova, M. V., W. P. A. Van Deursen, and T. A. Buishand, 2003: Assessing future discharge of the river Rhine using regional climate model integrations and a hydrological model. Climate Res., 23, 233-246, https://doi.org/10.3354/cr023233.

Themeß1, M. J., A. Gobiet, and A. Leuprecht, 2011: Empiricalstatistical downscaling and error correction of daily precipitation from regional climate models. Int. J. Climatol., 31, 1530-1544, https://doi.org/10.1002/joc.2168.

Toews, M. W., D. M. Allen, and P. H. Whitfield, 2009: Recharge sensitivity to local and regional precipitation in semiarid midlatitude regions. Water Resour. Res., 45, W06404, https:// doi.org/10.1029/2007WR006763.

Tomita, T., T. Yamaura, and T. Hashimoto, 2011: Interannual variability of the baiu season near Japan evaluated from the equivalent potential temperature. J. Meteor. Soc. Japan, 89, 517-537, https://doi.org/10.2151/jmsj.2011-507.

Ultsch, A., and H. P. Siemon, 1990: Kohonen's self organizing feature maps for exploratory data analysis. Proc. Int. Neural Networks Conf. 1990, Paris, France, INCC, 305-308.

Wang, Y., L. R. Leung, J. L. McGregor, D.-K. Lee, W.-C. Wang, Y. Ding, and F. Kimura, 2004: Regional climate modeling: Progress, challenges, and prospects. J. Meteor. Soc. Japan, 82, 1599-1628, https://doi.org/10.2151/jmsj.82.1599.

Zolina, O., C. Simmer, K. Belyaev, A. Kapala, and S. Gulev, 2009: Improving estimates of heavy and extreme precipitation using daily records from European rain gauges. J. Hydrometeor., 10, 701-716, https://doi.org/10.1175/2008JHM1055.1. 